\title{
Solution-enhanced dispersion by supercritical fluids: an ecofriendly nanonization approach for processing biomaterials and pharmaceutical compounds
}

This article was published in the following Dove Press journal:

International Journal of Nanomedicine

\author{
Ranjith Kumar Kankala ${ }^{1-3, *}$ \\ Biao-Qi Chen ${ }^{1,2, *}$ \\ Chen-Guang Liu',2 \\ Han-Xiao Tang ${ }^{1,2}$ \\ Shi-Bin Wang ${ }^{1-3}$ \\ Ai-Zheng Chen ${ }^{1-3}$ \\ 'College of Chemical Engineering, \\ Huaqiao University, Xiamen, People's \\ Republic of China; ${ }^{2}$ Institute of \\ Biomaterials and Tissue Engineering, \\ Huaqiao University, Xiamen, People's \\ Republic of China; ${ }^{3}$ Fujian Provincial \\ Key Laboratory of Biochemical \\ Technology (Huaqiao University), \\ Xiamen, People's Republic of China \\ *These authors contributed equally \\ to this work
}

\begin{abstract}
In recent years, the supercritical fluid (SCF) technology has attracted enormous interest from researchers over the traditional pharmaceutical manufacturing strategies due to the environmentally benign nature and economically promising character of SCFs. Among all the SCF-assisted processes for particle formation, the solution-enhanced dispersion by supercritical fluids (SEDS) process is perhaps one of the most efficient methods to fabricate the biomaterials and pharmaceutical compounds at an arbitrary gauge, ranging from micro- to nanoscale. The resultant miniature-sized particles from the SEDS process offer enhanced features concerning their physical attributes such as bioavailability enhancement due to their high surface area. First, we provide a brief description of SCFs and their behavior as an anti-solvent in SCF-assisted processing. Then, we aim to give a brief overview of the SEDS process as well as its modified prototypes, highlighting the pros and cons of the particular modification. We then emphasize the effects of various processing constraints such as temperature, pressure, SCF as well as organic solvents (if used) and their flow rates, and the concentration of drug/polymer, among others, on particle formation with respect to the particle size distribution, precipitation yield, and morphologic attributes. Next, we aim to systematically discuss the application of the SEDS technique in producing therapeutic nano-sized formulations by operating the drugs alone or in combination with the biodegradable polymers for the application focusing oral, pulmonary, and transdermal as well as implantable delivery with a set of examples. We finally summarize with perspectives.
\end{abstract}

Keywords: controlled release, anti-solvent, nanonization, drug delivery, polymeric carriers, parameters effect

\section{Introduction}

Recently, the supercritical fluid (SCF) technology has garnered enormous attention from researchers in numerous fields such as pharmaceutical and food as well as nutraceutical industries intended for various applications. ${ }^{1-3}$ This high-pressure technology has been widely adopted in the past few decades for obtaining products due to the environmentally benign nature and economically promising character of SCFs. ${ }^{4}$ Despite their success in particle formation during the processing of pharmaceutical actives, various traditional methods (milling, freeze drying, and spraying) still suffer from several limitations such as formulation instability, broad particle size distribution, and low drug loading efficiency, among others. ${ }^{5}$ In some cases, the processing of particle formation is extended to obtain uniform size distribution by subsequent
College of Chemical Engineering, Huaqiao

University, 668, Jimei Avenue, Xiamen

36I02I, People's Republic of China

Tel +865926162326

Fax +865926162326

Email azchen@hqu.edu.cn 
milling and sieving, which often result in the damage of sensitive biomolecules due to high shear forces. ${ }^{6,7}$ In addition, most of these processes usually rely on the utilization of large amounts of organic solvents, which result in product damage, toxicity, inflammability, and biocompatibility issues, among others. ${ }^{8}$ To this end, SCFs take advantage of the benign solvents, that is, $\mathrm{CO}_{2}$ and water, to circumvent the problems associated with the conventional approaches for precipitation of drugs either alone or in combination with the biodegradable polymers. ${ }^{9}$ Therefore, these SCFs act as an effective substitute for organic solvents in fabricating the pharmaceutical products. ${ }^{4,6}$

More often, SCFs as benign solvents offer considerable interest in pharmaceutical manufacturing processes because of their solvating power in separating the components and momentous changes in their physicochemical properties beyond the critical point. ${ }^{10}$ Moreover, other benefits of SCFs include solubilizing ability and ease of recycling, among others. The physical properties of SCFs (namely, density, viscosity, solvency, and diffusivity) that exist amid both liquid and gas can be easily altered by adjusting the critical conditions (pressure and temperature) during the processing of solutes..$^{8,9,11,12}$ In this framework, other SCFs such as water and solvents such as $\mathrm{CO}_{2}$ /ethanol mixture, acetone, nitrous oxide, propane, diethyl ether, trifluoromethane, and chlorodifluoromethane are operated at their corresponding supercritical conditions. ${ }^{10,12-18}$ The distinctive properties of these SCFs, including the critical parameters and other attributes such as solubility, have been already reported elsewhere. ${ }^{19}$ Among all the SCFs available, supercritical $\mathrm{CO}_{2}\left(\mathrm{SC}-\mathrm{CO}_{2}\right)$ has attracted enormous interest from researchers due to its wide adaptability, safety, cost-effectiveness, and requiring mild conditions for operation (temperature $304 \mathrm{~K} / 31.1^{\circ} \mathrm{C}$ and pressure $7.38 \mathrm{MPa} / 73.8$ bar) under ambient circumstances. ${ }^{10}$ Moreover, it should be noted that $\mathrm{SC}-\mathrm{CO}_{2}$ is recognized as safe by the United States Food and Drug Administration in pharmaceutical manufacturing ${ }^{20}$ as it is nonreactive, nontoxic, non-polluting, innocuous, and non-flammable..$^{9,10}$ It also offers several advantages which are highly favorable for particle fabrication, such as high volatility, low cohesive energy density, and low polarizability per unit volume, among others. ${ }^{12}$ Moreover, the unique physical properties of $\mathrm{SC}-\mathrm{CO}_{2}$, such as density, diffusivity solvency, and viscosity, can be manipulated beyond its critical point by adjusting the temperature and pressure. ${ }^{10}$

Increasing demand for particle fabrication of various active pharmaceutical ingredients (APIs) and investigations

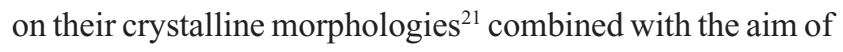

overcoming the limitations of currently available traditional methods (ie, particle destruction as well as impairment of bioactivity by strong shear forces, varied particle size distribution, and others), ${ }^{5}$ have garnered enormous attention of researchers toward the SCF technology. This technology is perhaps one of the rapidly evolving processes with many variants since its first report in $1879 .{ }^{22}$ Different variants of the SCF technology for particle fabrication are categorized based on the behavior of SCF, such as "solvent" (rapid expansion of supercritical solutions), ${ }^{23}$ "solute" (particle formation from gas-saturated solutions), ${ }^{24}$ "anti-solvent" (supercritical anti-solvent $[\mathrm{SAS}],{ }^{25}$ and its variants ${ }^{15,26-31}$ ), "reagent", ${ }^{32}$ and others such as supercritical-assisted atomization process ${ }^{10,33,34}$ and depressurization of an expanded liquid organic solution. ${ }^{15,35}$ Despite the variance in the behavior, SCF acts as a re-precipitation aid for rapid, uniform, as well as smooth nucleation of solutes (drug and/ or polymer) in all the above-mentioned processes intended for particle fabrication. ${ }^{10}$ Moreover, the performance efficacy of these processes utterly depends on the selection of an appropriate solvent and fine-tuning of the critical parameters. $^{22}$

\section{SAS process}

The SAS precipitation process has attracted widespread attention due to its distinctive advantages and ability to circumvent the processing limitations of conventional particle fabrication methods and other SCF processes such as rapid expansion of supercritical solutions. ${ }^{10,36} \mathrm{As} \mathrm{SC}-\mathrm{CO}_{2}$ is a relatively poor solvent for most of the pharmaceutical compounds and high-molecular-weight polymers under mild conditions (temperature $<100^{\circ} \mathrm{C}$, pressure $<350$ bar) and the utilization of co-solvents became impractical in their solubility improvement, the anti-solvent or non-solvent properties of it have been explored. ${ }^{12}$ This process is highly suitable to fabricate the solutes that are practically insoluble in SCFs. The name SAS was coined based on the behavior of SCF, where it acts as an anti-solvent with the solute (API/polymer). ${ }^{9}$ Bleich et al applied the SCF as an anti-solvent for the first time and encapsulated hyoscine butyl bromide into the poly(L-lactic acid) (PLLA) microparticles via co-precipitation using a mixture of solvents (methanol and dichloromethane [DCM]). ${ }^{37}$ In the past two decades, tremendous progress has been evidenced by the advancements of SAS for fabricating the polymer-based micro- or nano-sized composites.

The particle fabrication via SAS process involves the following sequential stages. Initially, the mixing of dispersed multiphase systems leads to the nucleation of solute, after 
attaining the supersaturation state. The surrounding molecules of the solute in the medium then start accumulating over the nucleus, and the crystal growth ultimately ends with agglomeration. As the nucleation phenomena are very rapid in this process, the mixing phase is exceptionally crucial, which defines the particle characteristics with respect to morphologic attributes and particle size distribution of the end product. ${ }^{1}$ The mechanism lying behind particle formation is that the blend of solvent, SCF, and solute expands to the supersaturation state and results in rapid nucleation, indicating the high mass transfer between the SCF and the solvent carrying the solute/API due to the high diffusivity and low viscosity of SCF. 9,22 Furthermore, the high diffusivity of SCF sequentially controls the phenomena of particle precipitation by initially increasing the volume of the solvent, which decreases its density and thereby declines the solvating power and eventually leads to the precipitation of the solute. ${ }^{9}$ Herein, the differences in densities of the solvent and SCF act as a potent driving force in the nucleation of solute. Subsequently, high supersaturation and smaller particle size can be achieved by rapid mixing of SCF-solution mixture. ${ }^{9}$ Moreover, the yield of this process majorly depends on the order of addition of SCF, solvent, and other substrates if used. ${ }^{10}$ In addition, various experimental attributes such as the critical conditions (ie, pressure and temperature), the chemical composition of solutes (polymer and/or APIs), and the type of organic solvent are required to be systematically optimized, which have been already discussed elsewhere. ${ }^{9,10}$

Among all the SCF-based processes for particle fabrication, the SAS process has become the most efficient and highly advantageous approach in producing micro- and nano-sized constructs with desired morphologies. ${ }^{10}$ This process often results in the formation of small-sized particles that yield a high specific surface area, which improves the release or solubility of APIs by improved mass transfer rates between the particle and the surrounding medium. ${ }^{38}$ In addition, this process has gained enormous importance due to high drug loading efficiency and rapid precipitation of solutes. More often, the process of particle fabrication is carried out at the ambient circumstances, which are highly suitable to process thermosensitive biomolecules such as genes and proteins. Moreover, this process is highly adaptable in performing continuous operations and due to the ease of scale-up for fine particle production. Other processes that work similar to the SAS technique include precipitation with compressed anti-solvent ${ }^{26}$ and gaseous anti-solvent. ${ }^{27}$ These methods comparatively have less operational problems than traditional SAS process; moreover, it is easy to practice these particle fabrication strategies at the industrial scale. . $^{10,27}$ Despite the significant advantages, the SAS process still possesses some disadvantages such as larger-sized droplets at the tip of the nozzle and extended washing period, leading to particle aggregation. ${ }^{9,25,39,40}$ However, this can be minimized by enhancing the mixing of solution using a vibrating ultrasonic processor to break/atomize the solution jet at high turbulence into tiny droplets in the sub-micron range. ${ }^{9}$ In addition, further advancements have been made to improve the micronization of SCF-insoluble solutes. ${ }^{10}$ Various modifications have been made in the SAS process to improve its functional attributes. The modified SAS processes include aerosol solvent extraction system, ${ }^{15}$ supercritical anti-solvent with enhanced mass transfer, ${ }^{31}$ supercritical fluid-assisted extraction of emulsions, ${ }^{41}$ and solution-enhanced dispersion by supercritical fluids (SEDS). ${ }^{28-30}$ Among all these SAS processes available, SEDS is the most advanced anti-solvent process for particle precipitation. In this review, we provide a comprehensive overview of this process based on the literature published in the past two decades related to drug delivery through various routes of administration. In addition, this review highlights the effects of critical parameters on the particle size, providing a vision for the future of SCF technology.

\section{SEDS process}

The SEDS process was developed by York and Hanna of Bradford University in the year 1996 to improve the performance efficiency of the traditional SAS process. ${ }^{42}$ On the other hand, this advanced process also minimizes the operating limitations of the aerosol solvent extraction system process and other SAS processes. ${ }^{10}$ The SEDS process is usually operated at a lesser drying time with increased mass transfer rates that are significantly different from the conventional SAS process in achieving miniaturesized droplets. ${ }^{14,42,43}$ The chief aim of the SEDS process is to produce uniform-sized fine particles in a single-phase equilibrium, while removing the organic solvent to deliver them in a dried form. Typically, the components (API and/or excipients) are initially dissolved in a suitable organic solvent by vigorous mixing, and then they are rapidly sprayed along with SCF through a specially designed coaxial nozzle into a high-pressure vessel. The mixture yields small-sized droplets due to jet breakup at the tip of the nozzle, subsequently resulting in the fine particles. Herewith, the nozzle as well as its specifications (predominantly the inner diameters) play a crucial role in the eventual particle size distribution. 


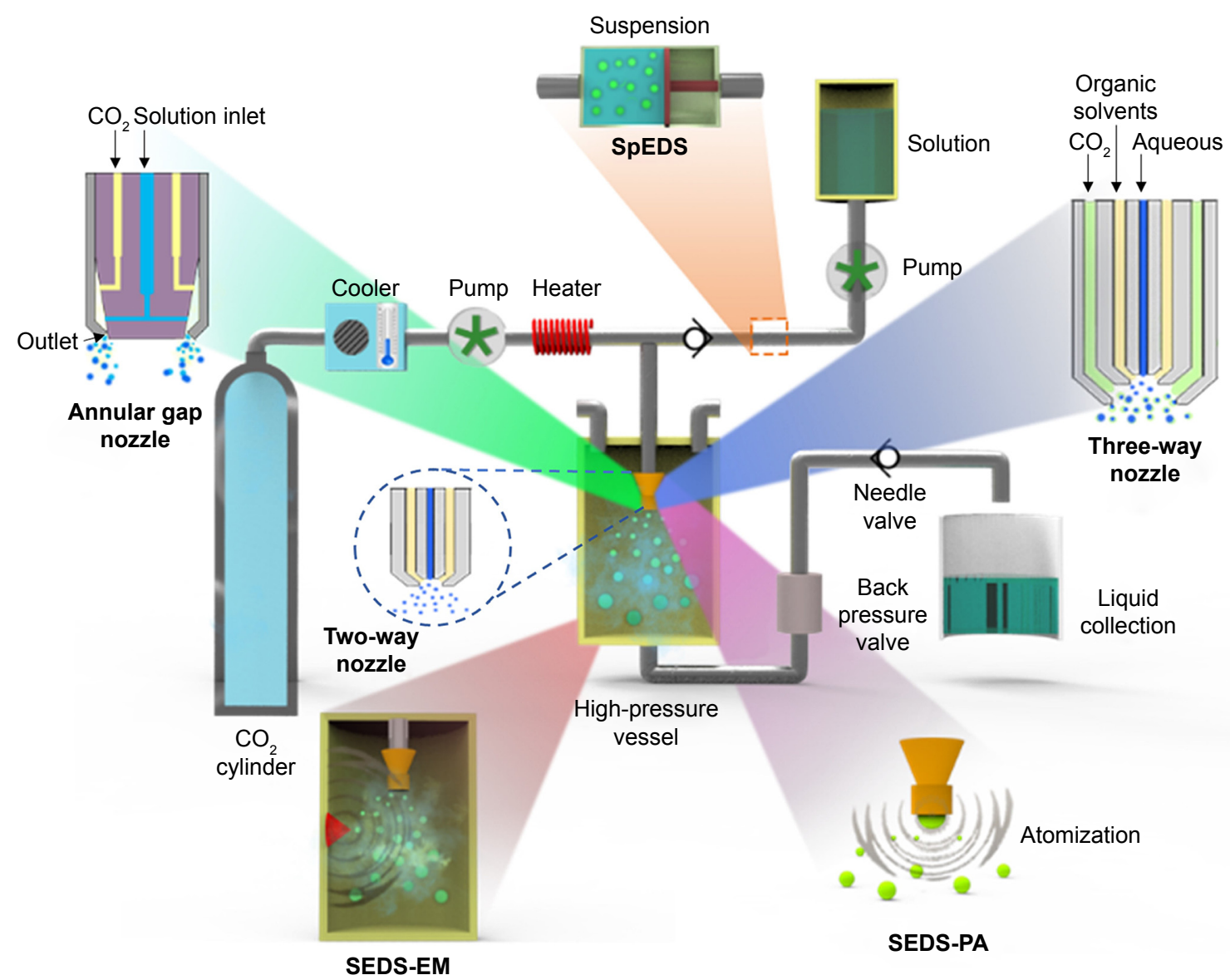

Figure I Conceptual representation of the SEDS process and its various modifications.

Abbreviations: SEDS, solution-enhanced dispersion by supercritical fluids; SEDS-EM, solution-enhanced dispersion by supercritical fluids with enhanced mass transfer; SEDS-PA, solution-enhanced dispersion by supercritical fluids - prefilming atomization; SpEDS, suspension-enhanced dispersion by supercritical fluids.

In addition, various processing conditions such as the flow rates of both $\mathrm{SC}-\mathrm{CO}_{2}$ and the drug solution and critical parameters should be optimized to facilitate better control over the particle size and morphology (Figure 1$).{ }^{38}$ During the co-precipitation of drug and polymer composite particles in this process, the components are required to be insoluble in SCF and they should possess mutual compatibility as well as excellent thermodynamic properties. Otherwise, it leads to a severe consequence of phase separation resulting in individual particles of drugs and polymers rather than drug-polymer composites.

As mentioned earlier, the particle formation in an antisolvent process utterly depends on the mass transfer ratio between SCF and the droplet-containing solute, subsequently the rate of solvent transfer into the SCF phase. ${ }^{38,44}$ Thus, the mass transfer at a high rate allows spontaneous nucleation and results in small-sized particles with no chance of agglomeration. ${ }^{28,38,44,45}$ To demonstrate these facts, two possible mechanisms have been proposed, such as the drop dispersion followed by the mass transfer between SCF and droplet and the micro-mixing of the solvent with SCF. ${ }^{1,46}$ However, the miscibility between SCF and the solvent predominantly determines the type of mechanism involved during the particle formation. ${ }^{1}$

Among all the SAS-based particle fabrication techniques available, the SEDS process holds numerous advantages such as production of ultrafine particles with a narrow and uniform particle size distribution enhancing the dissolution rates of the APIs, high yields of polymer-based micro- and nano-sized composites, minimal agglomeration of particles, acceptable limits of residual solvents when operated at a reduced drying time, and ease of polymer coating over various particulate forms of APIs resulting in core-shell composites with sustained drug release ability, among others. ${ }^{47-50}$ Moreover, this process is highly suitable for operating the water-soluble compounds by spraying the aqueous solutions along with the organic solvent separately through a coaxial three-compartment nozzle. ${ }^{10,51-55}$ However, there still exist some problems such as small processing capacity and easy blockage of the nozzle. In addition, the minor disadvantage 
of this process is that the SCF is completely miscible with the solution feed above the critical pressure (exists as a single phase), ${ }^{1}$ which may result in a broad particle size distribution during scale-up. ${ }^{46}$

\section{Modified SEDS processes}

One of the critical steps of particle fabrication by SEDS is the formation of smaller-sized droplets at the tip of the nozzle. ${ }^{56}$ Herewith, the nozzle and its specifications play a critical role during SEDS processing, which can be altered to adjust the jet breakup for fine particle formation. In this vein, various designs of atomizer have been developed, such as coaxial nozzles, internal twin-fluid mixing nozzles, four-pinhole nozzle, and an annular gap nozzle..$^{5,57}$ In addition, tremendous progress has been evidenced by the advancements of SEDS in enhancing the efficiency of particle formation and overcoming the processing damage issues. Other variants (Figure 1) of the SEDS process include solution-enhanced dispersion by supercritical fluids - prefilming atomization, solution-enhanced dispersion by supercritical fluids with enhanced mass transfer, and suspension-enhanced dispersion by supercritical fluids (SpEDS).

\section{Two-channel nozzle}

In the SEDS process, the two-way coaxial nozzle is commonly used to spray the SCF and the solution feed containing the active substrate separately into the high-pressure vessel under controlled critical conditions (Figure 1). ${ }^{55}$ During particle formation, the turbulent flow of SCF allows the solution containing the substrates to split rapidly into tiny droplets of partly mixed and highly supersaturated solution that are sprayed into the high-pressure vessel as a jet. The nucleation of solute then starts at the tip of the two-way nozzle chamber, and subsequently, the particle growth ends the process in the precipitation vessel. ${ }^{52,55}$

\section{Three-channel nozzle}

A coaxial three-channel system can be applied for the micronization/nanonization of poorly water-soluble drugs or drug-polymer composites. This system facilitates the flow of three solvents ( $\mathrm{SC}-\mathrm{CO}_{2}$, aqueous drug solution, and the polymer dissolved in an organic solvent) distinctly into the precipitation vessel to overcome the compatibility issues (Figure 1). ${ }^{58}$ In general, the mixture of drug and polymer dissolved in the same solvent (such as acetone, DCM, or a mixture of solvents) is introduced through a two-way channel-assisted spraying method, which leads to the risk of organic solvents damaging the biomolecules. To overcome this limitation, a multi-channel nozzle system is used to spray the sensitive biomolecules (mostly peptides, proteins, and genes) separately during the SEDS processing. However, it should be noted that the geometric dimensions of the nozzle play a crucial role in influencing the morphology of the micro-/nanoparticles in the three-channel nozzle system. ${ }^{58}$ In one case, Zhang et al fabricated microparticles by using the three-channel nozzle system with different inner diameters in the range of 50-2,000 $\mu \mathrm{m}$ and their ends on the same plane. ${ }^{58}$ The inner diameters of the different channels in the nozzle had played a crucial role in the size of the initially formed droplets and mass diffusion between the solution containing the APIs and $\mathrm{SC}-\mathrm{CO}_{2} \cdot{ }^{59}$ However, in some instances, previous reports have indicated that the initial droplet size had no significant effect on the eventual sizes of the particles. ${ }^{60}$

\section{Annular gap nozzle}

The other interesting type of nozzle in SEDS processing is the annular gap nozzle. This nozzle system has been explicitly designed to enhance the surface area of exposure of the solution with $\mathrm{SC}-\mathrm{CO}_{2}$ (Figure 1). Herein, $\mathrm{SC}-\mathrm{CO}_{2}$ and the drug/polymer solution that are introduced separately through different channels are mixed in the annular gap of the nozzle, and they are then sprayed rapidly into the high-pressure vessel to augment the mass transfer rates between the SCF and the solution feed containing the active substrate. Moreover, this approach is highly advantageous over others because the distance within the annular gap of the nozzle can be adjusted based on the particle size requirement. ${ }^{57}$

\section{Solution-enhanced dispersion by supercritical fluids - prefilming atomization}

This process is different from the conventional SEDS process as it utilizes a specialized prefilming twin-fluid atomizer that increases the mass transfer rate between the SCF and the solution feed (Figure 1). The principle lying behind particle formation is that the fluid intended for atomization is driven along the coaxial annular passage within the nozzle as thin swirl liquid film sheets, ${ }^{61}$ which separate after interacting with the dense gas at the tip and result in fine droplets. Further, the mixing of both the liquids, that is, the SCF and the solution feed, is intensified for enhancement of mass transfer rates, which eventually result in fine particles. ${ }^{61-63}$ Previous reports have also indicated that the existence of atomizing air in the nozzle chamber might result in a faster reduction in the breakup length, and this became even stronger when swirling was imparted to the atomizing air. ${ }^{61,64}$ 


\section{Solution-enhanced dispersion by supercritical fluids with enhanced mass transfer}

The solution-enhanced dispersion by supercritical fluids with enhanced mass transfer process is an enhanced mass transfer precipitation technique that was developed by combining the conventional SEDS process with the auxiliary ultrasonication setup (Figure 1). The operation of this process is similar to that of the conventional SEDS process, but the mixture of SCF and the solution feed is sprayed onto the vibrating surface at an ultrasonic frequency, which augments the mass transfer between the solution and the SCF, thus resulting in a significant reduction of the particle size approximately by several folds. ${ }^{65}$ In particular, the size of the droplets in the ultrasonic field is reduced with an increase in the ultrasound energy input, which subsequently improves the mass transfer rate and mixing between the droplets and $\mathrm{SC}-\mathrm{CO}_{2} .{ }^{65}$ Hence, this phenomenon demonstrates that the attached ultrasound transducer can efficiently control the particle size.

\section{Suspension-enhanced dispersion by supercritical fluids}

SpEDS is one of the most advanced processes that have been developed for broadening the application of SEDS and overcoming its processing damage issues. ${ }^{29}$ The device setup of this process is almost similar to SEDS, but SpEDS has an auxiliary injector equipped with a piston to efficiently pump the loaded suspension of the drug or the drug-polymer mixture (Figure 1). ${ }^{29,30}$ The use of injector setup in this process is highly advantageous as it avoids obstruction of the one-way valve and damage of the high-pressure pump during pumping of the particle suspension into the high-pressure vessel. ${ }^{29,66,67}$ This process predominantly results in core-shell structured drug-polymer composites at an arbitrary size ranging from microscale to nanoscale with high drug encapsulation efficiency. Moreover, these core-shell nanocomposites offer a significant advantage of sustained drug release from the core (discussed under the "Applications" section).

\section{Effects of various processing parameters on particle size}

The SEDS process is often preferred to precipitate particles at an arbitrary size ranging from micro- to nanometer scale with uniform size distribution and smooth surfaces. These fine-sized particles will eventually augment the bioavailability of most of the APIs due to their high surface area. More often, this process is used to operate poorly water-soluble drugs/biodegradable polymers that are aimed for the controlled release of drugs. To achieve this goal, the processing parameters of SEDS must be optimized with good care for fine particle formation, such as suitable operating conditions, appropriate selection of suitable polymers based on their solubility, and selection of the proper solvent. Herewith, we emphasize the effect of various operating parameters of the SEDS process, such as critical conditions (pressure and temperature), solute (drug or polymer) and solution concentration, a type of organic solvent as well as SCF, flow rates of SCF and solutions, and others such as nozzle diameter, atomization frequency, and humidity, on the size of the particle and its morphologic attributes.

\section{Critical conditions}

The critical parameters that play a crucial role during operation of the SCF technology are pressure and temperature. These parameters are the predominant deciding factors that indicate the state of existence of any supercritical solvent. Herewith, the solvents above the critical conditions exist as a single phase, where their physical properties are intermediate between liquid and gas and can be easily manipulated by adjusting the critical conditions. This adjustment is beneficial where they could be altered during the processing of pharmaceutical additives for attaining better yields of the product. However, it should be noted that the variations in these conditions often show significant influence on not only the disparity in physical properties of the SCFs but also the morphologic and structural attributes of the formulation.

\section{Pressure}

In general, the SCF-assisted processing at increased pressure, that is, above the critical point, often results in a significant reduction of the particle size to the extent of nano-size range due to volumetric expansion of the solvent and its solubility improvement in the SCF. Contrariwise, it results in an irregular morphology below the critical point of SCF. In addition, the increase in pressure augments the diffusion of SCF into the solvent, ensuing supersaturation that subsequently results in small-sized particles. ${ }^{68-70}$ However, the changes in the pressure had no significant influence on the biological activity of the sensitive molecules such as enzymes. ${ }^{71}$

\section{Temperature}

Temperature is another critical parameter that plays a very crucial role in the particle fabrication processes. The SEDS process is generally operated at around $40^{\circ} \mathrm{C}$, where no significant effects are observed on the particle. However, 
the solute merely experiences reduction in its density with a rise in temperature, which subsequently reduces its solubility in the organic solvent. These consequences result in slower supersaturation and longer growth time, yielding the large-sized particles. ${ }^{72}$ Herewith, the balance of the growth time and nucleation speed plays a vital role in deciding the eventual particle size of the product.

Similar to pressure, changes in temperature also result in variations in the morphologic and structural attributes of the particles. In some instances, an increase in temperature results in severe aggregation of the particles with irregular surfaces due to collisions among the microparticles and vice versa ${ }^{68-70}$ To this end, the drug loading efficiency in the polymeric carriers is reduced during these conditions due to phase separation, which was articulated in a thermodynamics point of view.

\section{Solute}

The foremost consideration of any substrate (drug/polymer) during the processing is its solubility in SCF. As $\mathrm{SC}-\mathrm{CO}_{2}$ is relatively a poor solvent, the anti-solvent processes are explored to operate the poorly SCF-soluble solutes by using organic solvents such as acetone, DCM, dimethyl sulfoxide (DMSO), and others to solubilize the materials, where SCF acts as an anti-solvent with respect to the substrate. Moreover, it should be noted that the structure and nature of drugs/ polymers and their physicochemical properties are essential factors for producing particles with desired drug encapsulation efficiency as well as particle size distribution with the SEDS process. For example, lipophilic drugs or SCF-soluble drugs are profoundly challenging for their precipitation or encapsulation in polymers. On the other hand, compared to the crystalline polymer or semi-crystalline polymer, amorphous polymers (eg, poly(lactic-co-glycolic acid) [PLGA]) are hard to crystallize and precipitate in the high-pressure vessel. These consequences often result in reduced drug loading efficiency and broader particle size distribution.

\section{Multiple polymers}

Preceding reports indicated that it is easy to precipitate and produce the small-sized microparticles from polymers in their crystalline form or semi-crystalline form (eg, PLLA). These forms of polymers are recrystallized well in the SEDS process through successive steps: initially nucleation, that is, the formation of the polymeric nucleus, followed by the growth phase, resulting in the desired composite particles in the amorphous form. ${ }^{10}$ However, it is difficult to process amorphous forms of polymers such as PLGA, as they eventually result in undesirable aggregates..$^{10}$ To overcome this limitation, the combination of biodegradable polymers (PLLA/PLGA) is preferred in some cases to produce microparticles within the acceptable mean particle size range. ${ }^{73}$ Moreover, the crystallinity of the polymeric microparticles is reduced after SEDS processing, such that the resultant microparticles in their amorphous state possess high degradation rate in vivo.

\section{Solution concentration}

In addition to the nature of the substrate, the concentration of a drug or a polymer in the solvent also plays a crucial role in determining the particle size and its distribution during SEDS processing. ${ }^{63}$ In an SCF-assisted process, the particle size of a substrate is usually increased with an increase in its concentration, which is correlated to the terms of enhanced nucleation and growth processes. In this framework, the injected dilute solutions often result in delayed saturation and subsequently the slower precipitation during the expansion of the droplet. ${ }^{63}$ These consequences eventually result in smallsized particles. Thus, nucleation is the dominant plausible mechanism in these circumstances. Contrariwise, increase in concentration results in enhancement of surface tension as well as the viscosity of the solution, which eventually result in the formation of large primary droplets. ${ }^{9,74}$ Herewith, the mechanism lying behind the particle growth correlates with the nucleation of solute due to rapid supersaturation, yielding the large-sized particles. ${ }^{56,63}$ Previous reports have indicated that the solutions at a lower concentration were highly beneficial for the formation of particles with uniform size distribution. However, the decrease in solution concentration, in turn, influences the loading efficiency of the drugs in the polymers. ${ }^{68}$

In an attempt to explore the effect of organic non-solvent concomitantly with the solution concentration on the particle size and shape in SEDS, Chen et al demonstrated that the addition of DCM into the ethanolic solutions resulted in an initial concentration with a high degree of saturation yielding the small-sized particles with a spherical shape. ${ }^{9,74}$ In this study, the authors described that the effect of solvent ratio was found to be prevailing on the particle sizes compared to that of the solution concentration. ${ }^{74}$ Moreover, they clarified that the solution concentration showed significant influence on the width of the particle. Together, they concluded that an increase in the degree of saturation with a decrease in the solution concentration had resulted in small-sized spherical particles. The strategy of utilizing non-solvent was highly cost-effective, as it results in the fabrication of particles at the lower consumption of $\mathrm{CO}_{2}{ }^{74}$ 


\section{Solvent}

In an anti-solvent process, various co-solvents are required to increase the solubility of a solute. The most preferred solvents include acetone, DMSO, methanol, chloroform, ethanol, isopropanol, and DCM, among others. However, the selection of an appropriate solvent plays a crucial role while formulating the drug delivery systems. The selection process primarily depends on the solubility of the solute (polymer/ drug) in the solvent and its compatibility with the SCF. In a few instances, a combination of solvents such as acetone/ $\mathrm{DMSO}^{59}$ and DCM/DMSO ${ }^{47,59}$ is also used at a determined ratio, such that one of them is highly volatile to induce significant volume of expansion and easy removal and the other solvent enhances the solubility of a solute. ${ }^{68}$ Moreover, it should be noted that the solvent selection is also based on the ratiometric solubility of polymer with the drug, because the drug should precipitate earlier for its encapsulation in the polymer. Furthermore, the entrapped drug may also result in diverse polymorphic forms in different solvents, which eventually guide the release of the drugs. ${ }^{75}$ In this context, some solvents may result in a reduced yield of the end product due to the following reasons: 1) the high viscosity of the solvent that leads to inadequate diffusion between the solvent and the anti-solvent and 2) the high solubility of a solute in the solvent leading to difficulty in its precipitation at a low concentration. ${ }^{47}$ To overcome this limitation, high saturation is achieved by using a non-solvent at a low concentration of the solute. Thus, the solute can rapidly precipitate and lead to micro-/nano-sized particles with uniform size distribution. ${ }^{76}$ In addition, the multiphase emulsions can be preferred in some instances instead of organic solvents to overcome the insolubility and inactivation of sensitive molecules such as genes or peptides.

\section{Solution flow rate}

In addition to the solute concentration, the particle size of a substrate depends on the solution flow rate during SCF processing. In general, an increase in the solution flow rate results in an increase of the size of the particles due to weak impingement of SC-CO $\mathrm{C}_{2}$ on the liquid film. ${ }^{56,72}$ However, it is also related to other parameters such as surface tension and viscosity of the liquid. In one case, Chen et al reported that the solution flow rate affects the shape of the particles. ${ }^{74}$ With an increase in flow rate above the normal level, the system resulted in particles with piriform shape, that is, more extended than a sphere. These consequences of the particle with different shapes concerning the flow rate can be explained well in relation to the hydrodynamic aspects of the liquid, that is, the variation in kinetic energy per unit mass of the liquid, which is appropriate to precipitate smallsized particles with narrow size distribution at a low flow rate and vice versa. ${ }^{68}$ In addition to the particle size, the flow rate also affects the drug loading efficiency in polymer-based delivery systems. In a way, an increase in the solution flow rate results in enhancement of their loading efficacy. In one case, the solution flow rate had shown combinatorial effects on the particle size. ${ }^{63}$ The particle diameter was increased in the beginning and then decreased with an increase in flow rate, demonstrating the influence of the rapid atomization of formed liquid sheets. The effective mechanisms that played a vital role during atomization were clearly explained by He et al. ${ }^{63}$ They explained that two different but complementary mechanisms are involved: 1) prompt atomization and 2) the wave mechanism during atomization. ${ }^{63,70}$ The mechanism of prompt atomization is generally correlated to the speed of liquid sheet at the edge of the atomizer tip, which is maintained low at a lower flow rate, resulting in an intense equivalent momentum transfer between the solution and $\mathrm{SC}-\mathrm{CO}_{2}$ and eventually disintegrates the sheet into fine droplets. ${ }^{63,70}$ The energy per unit mass of liquid in these conditions that gained from the dense gas to fragment the sheet into drops decreases with increase in the solution flow rate at a constant $V \mathrm{c}$ (ie, flow rate of $\mathrm{CO}_{2}$ at the standard state [temperature $273 \mathrm{~K}$, pressure $101,325 \mathrm{~Pa}$ ] in L/min), which increases the droplet size and, subsequently, the particle size of the end product. ${ }^{63,70}$

\section{Supercritical fluid}

SCF in these anti-solvent processes acts not only as an anti-solvent, but also as a spray enhancer and a reprecipitation aid. In general, SCFs have no significant influence on the synthesized formulation in the anti-solvent processes. However, the mean diameter of the particles generated from a semi-crystalline form of polymers depends on the density of the SCF. ${ }^{77}$ During the SEDS processing of substrates, the pumped SCF is completely miscible with the solution feed above the critical pressure and the mixture exists as a single phase. The resultant particles produced by the SEDS process possess attractive physicochemical properties such as reduced tensile strength facilitating these readily dispersible fine particles for aerosol formulations, ${ }^{78}$ wafer-like morphology with a higher surface area to improve their bioavailability in vivo, ${ }^{79}$ and producing dosage forms with reduced dose variability. ${ }^{80}$

The SCF technology is often operated using one of the available supercritical solvents. Interestingly, Ghaderi et al 
have improved the SEDS process by using a combination of SCFs $\left(\mathrm{N}_{2}\right.$ and $\left.\mathrm{CO}_{2}\right)$ to overcome the severe flocculation caused during the production of polymeric microparticles. ${ }^{81}$ The obtained polymer dispersions using a combination of gases were in smaller sizes compared to those of products obtained when $\mathrm{CO}_{2}$ alone was utilized, due to enhancement of the plasticizing effect of SCF. These particles with successful drug entrapment resulted in the controlled release of drugs. ${ }^{81,82}$

\section{SCF flow rate}

Similar to the solution flow rate, the flow rate of SCF has a minor influence on the particle size of the resultant products, which can be adjusted by optimizing the conditions. ${ }^{63}$ In general, an increase in the flow rate of SCF results in reduction of particle size due to the effects concerning the consolidating forces of surface tension and viscosity of the liquids that sturdily oppose the disrupting action of externally applied aerodynamic forces in a twin-fluid atomization process. Henceforth, the impingement of dense gas on the liquid film is reinforced and results in the formation of fine droplets. ${ }^{63}$

\section{Miscellaneous factors}

\section{Nozzle and atomization}

The SEDS process involves the spraying of various constituents through a specially designed coaxial nozzle that is convenient for the parallel flow of both the liquids, that is, SCF as well as the solution containing the active substrate, separately. Despite the advantages, the utilization of coaxial nozzle still faces a limitation of generating a high-shear force during the discharge of the constituents from the pump, which damages the labile biomolecules such as genes and peptides. This could be addressed by utilizing the three-channel nozzle system. In addition, it should be noted that the diameter of the nozzle plays a critical role in the eventual size of the particles.

Furthermore, atomization of liquids in the nozzle is one of the critical steps that plays a crucial role during particle formation in the SEDS process. ${ }^{56}$ These specially designed devices (ie, atomizers) efficiently atomize a solution of active substances, intensify its mixing with the SCF in the nozzle, and enhance the mass transfer rates between them for fine particle formation. ${ }^{56,57,63}$ The solution that is intended to be atomized is initially driven along a coaxial annular passage resulting in a thin swirl film at a thickness of $10 \mu \mathrm{m}$. The $\mathrm{SC}-\mathrm{CO}_{2}$ stream for atomization then impinges the formed thin swirl film at the tip of the atomizer and generates shear forces which disintegrate the film into ultrafine droplets. Further intensification of mixing may result in the formation of uniform-sized particles. ${ }^{56}$ However, a high quality of atomization could yield ultrafine primary droplets, ensuing enhancement of the two-way mass transfer rates and subsequently resulting in small-sized particles at a significant nucleation rate. ${ }^{56,62}$

\section{Humidity}

Humidity is another crucial factor that significantly influences the quality of the end product during SCF-assisted processing. In general, the particle adhesion scenario and wetting phenomena are the resultant effects of humidity, and they vary with the processing conditions as well. A study has compared the materials obtained from SEDS processing with the products obtained from the conventional micronization method. ${ }^{83}$ This investigation demonstrated that the product obtained from the SEDS process was more sensitive to humidity. The effects of humidity on particle morphology were captured by atomic force microscopy, indicating that the changes were due to surface chemistry differences involving various factors such as electrostatic, capillary, and van der Waals forces and the surface free energy of the particle, which played critical roles in particle adhesion. ${ }^{83}$

\section{Problems}

Despite their efficacy and advancements in producing various polymeric constructs, the SEDS process still faces a minor problem of poor recovery as single nano-units during the synthesis of nanoparticle formulations. ${ }^{84}$ More often, the nanoparticles in their dry form tend to disperse in the precipitation chamber and are very difficult to collect. To overcome this limitation, Torino et al proposed an innovative strategy that worked on the principle of processing the soft aggregates of the collected nanoparticles by ultrafiltration, ultracentrifugation, or ultrasound-based techniques for their separation as single nano-units. ${ }^{84}$

\section{Applications Drug delivery}

Drug delivery usually relies on various formulations and approaches for conveying APIs (drugs/proteins/genes) to accomplish the desired therapeutic effects. ${ }^{10}$ The foremost aim of any technology that produces these formulations/ dosage forms is the efficient delivery of drugs to the right target as far as the health care field is concerned. The SCF technology is perhaps one of them that has gained enormous attention in the past few decades due to its numerous advantages and ability to overcome the limitations associated with the traditional methods, such as physical instability of 
the resultant product, multi-step procedures, and usually relying on large amounts of organic solvents, among others. ${ }^{10,12,38,45,85-88}$ The unique adaptive properties of SCFs, such as solvating power, large compressibility, and others, provide many better ways of particle fabrication for drug delivery. ${ }^{10,88,89}$ Another significant advantage of this technology is that it allows single-step fabrication of particles with uniform size distribution, which is difficult to achieve by traditional methods. Moreover, the SCF-assisted processes have been used to synthesize various formulations with respect to different categories as well as routes of administration, which have been discussed elsewhere. ${ }^{10}$ This technology has been used to process the APIs alone or in combination with various biodegradable polymeric carriers for the enhancement of bioavailability. ${ }^{10}$ In this framework, the SEDS process, the most advanced prototype of the SCF technology, has been widely used in the pharmaceutical manufacturing process for producing the dosage forms intended for oral, pulmonary, and transdermal routes of administration. Herewith, we give a detailed view of processing APIs via the SEDS process with a set of examples.

\section{Micro-/nanonization of pure drug}

Drug delivery has been associated with some critical challenges such as solubility and diffusion, which need to be addressed for the effective conveyance of therapeutic cargo. More often, the new chemical entities also suffer from poor solubility and stability issues. In addition, the dissolution of the APIs after delivery has remained a significant concern in formulating dosage forms, especially for the drugs with a narrow therapeutic index. To overcome this limitation, numerous studies have indicated that reduction in the size of the particles is one of the ways for enhancing the therapeutic efficacy of such drugs. This has been well achieved by micronization or nanonization of drugs, which results in enhancement of the available surface area of exposure to the solvent and, subsequently, the dissolution of poorly water-soluble drugs, and eventually their therapeutic efficiency. Moreover, these nano-sized products have been used for various biomedical applications such as bioimaging, tissue engineering, in vitro diagnostics and implants, among others (Table 1). ${ }^{3,10,88,90}$

Various techniques such as grinding, milling, crushing, electrospinning, and spray drying, among others, are also available to produce micro-sized as well as nano-sized particles of various pharmaceutical compounds. ${ }^{10,74}$ However, the applicability of these conventional processes is limited due to the need for large amounts of organic solvents. In some instances, these processes yield broad particle size distribution in the end product, thermal denaturing owing to high processing temperatures, and excessive surface

Table I Examples showing the nanonization/micronization of pure drugs using the SEDS process

\begin{tabular}{|c|c|c|c|c|}
\hline Material & Solvent & Particle size $(\mu \mathrm{m})$ & Purpose of delivery & Reference \\
\hline Albuterol sulfate & $\mathrm{MeOH}, \mathrm{DCM}$ & 3.1 & Bioavailability enhancement & 80 \\
\hline Baicalein & DCM, DMSO & 0.6 & Bioavailability enhancement & 47 \\
\hline \multirow[t]{2}{*}{ Budesonide } & Acetone & $1-3$ & Inhalation powders & 80 \\
\hline & Acetone, $\mathrm{MeOH}$ & $1-3,5-30$ & Particulate pharmaceuticals & 75 \\
\hline \multirow[t]{2}{*}{ Carotene } & DCM & $3.2-96.8$ & Controlled delivery in food products & 92 \\
\hline & DCM & $2-5,0.02-0.205$ & Particulate pharmaceuticals & 65 \\
\hline Cefquinome & DMSO & 0.73 & Bioavailability enhancement & 57 \\
\hline Chelerythrine & $\mathrm{MeOH}$ & $0.1-1$ & Bioavailability enhancement & 70 \\
\hline \multirow[t]{2}{*}{ Curcumin } & Acetone & $0.23-0.24$ & Bioavailability enhancement & 94 \\
\hline & & $0.325-1.024$ & & 95 \\
\hline Flunisolide & Acetone, $\mathrm{MeOH}$ & $>2$ & Particulate pharmaceuticals & 75 \\
\hline Human growth hormone & Isopropanol & $1-6$ & Bioavailability enhancement & 96 \\
\hline Immunoglobulin G & Sodium citrate, Tween-80, EtOH & - & Biopharmaceutical powders & 97 \\
\hline Lycopene & EA & $0.075-3.6$ & Bioavailability enhancement & 98 \\
\hline Lysozyme & DMSO & $\mathrm{I}-5$ & Bioavailability enhancement & 71 \\
\hline Methotrexate & Acetone, DMSO & $0.45-1.35$ & Bioavailability enhancement & 59 \\
\hline Naringenin & Acetone, DCM & 0.61 & Bioavailability enhancement & 99 \\
\hline Nicotinic acid & $\mathrm{MeOH}$ & $1-5$ & Pulmonary delivery & 100 \\
\hline Puerarin & $\mathrm{DCM}, \mathrm{EtOH}$ & 0.19 & Bioavailability enhancement & 74 \\
\hline Quercetin & EA & $\mathrm{I}-\mathrm{I} .5$ & Particulate pharmaceuticals & 101 \\
\hline Resveratrol & Acetone, DCM (4:6, v:v) & 0.22 & Bioavailability enhancement & 102 \\
\hline Salbutamol & - & $\mathrm{I}-5$ & Inhalation powders & 103 \\
\hline
\end{tabular}

Abbreviations: DCM, dichloromethane; DMSO, dimethyl sulfoxide; EA, ethyl acetate; EtOH, ethanol; $\mathrm{MeOH}$, methanol; SEDS, solution-enhanced dispersion by supercritical fluids. 
changes or roughness of products, thereby manipulating the bioavailability of the drugs. ${ }^{10}$ Moreover, the process may lead to product contamination and damage of the sensitive biomolecules in some cases because of the strong shearing forces and heat generated by them..$^{59,90,91}$

Among all the SCF-assisted processes, the SEDS technique is one of the efficient approaches for the nanonization of drugs as the scope of fine particle formation is significantly high due to excessive mass transfer rates, intensified mixing, and the formation of tiny droplets leading to ultrafine particles with narrow size distribution. ${ }^{59,91}$ This process often results in fine-sized particulates of drugs at a high efficiency as it utilizes an anti-solvent that acts as a spray enhancer by the mechanical effect. ${ }^{65,92,93}$ The extemporaneous contact of highspeed liquid jet streams with the SCF generates a uniformly dispersed mixture and eventually leads to prompt precipitation of the nano-sized particles. The customized operation of the SEDS process is very fast, such that it results in a change of physical state of the solute from a regular crystalline state into an amorphous form, where it has no chance and scope to consolidate the solute in its systematic crystalline patterns during recrystallization. ${ }^{59,90,91}$ In the thermodynamic point of view, the solutes in their crystalline equivalents happen to be in the lowest energy state due to their regularly arranged basic structural units. ${ }^{90}$ Nevertheless, the transformation in their physical state would result in superfluous free energy and entropy, and these consequences would undoubtedly facilitate an upsurge in the dissolution rate of drugs and eventually their bioavailability (Figure 2). ${ }^{59,90}$

In general, the SEDS process is not only used for operating poorly water-soluble drugs, but also widely applied for the precipitation of protein- and peptide-based drugs that are intended to be absorbed from noninvasive routes of administration such as pulmonary and transdermal delivery. ${ }^{96,97}$ Despite the success and reliability in formulating the therapeutic proteins by the SEDS process, the longterm stability may be compromised due to the undesirable chemical degradation mechanisms and conformational alterations that can affect the primary, secondary, and/or tertiary structures of a protein. ${ }^{96}$ However, extensive studies are required to overcome these limitations and explore the processing of sensitive biomacromolecules alone.

\section{Polymeric carriers \\ Controlled drug release}

In recent times, various biodegradable as well as biocompatible polymers have attracted significant attention from researchers in preparing the controlled delivery systems due to the ease of drug impregnation, ability to convey high amounts of therapeutic cargo, sustained release of drugs from the matrix by preserving the levels in the therapeutic window, reduction in side effects of drugs, enhancement of bioavailability, and biodegradability, among others. ${ }^{10,104-106}$ In addition, the incorporation of drugs in a suitable carrier facilitates the improvement of the fate of the drug by changing its delivery pattern (Figure 3 ). However, the ability to achieve control over various physical parameters such as morphology, size, stimuli-responsive and desired release characteristics is highly challenging during the formulation of polymeric carriers. These parameters utterly depend on the selection of the polymers by considering their thermosensitivity as well as polarity. Moreover, the critical aspect that should be considered during the processing of polymeric carriers is their solubility in SCFs. However, in the SEDS process, it could be surpassed by dissolving them in the desired organic solvents, which could be eventually removed through extraction after particle formation. These processes that utilize SCFs as antisolvents for the production of many pharmaceutical products

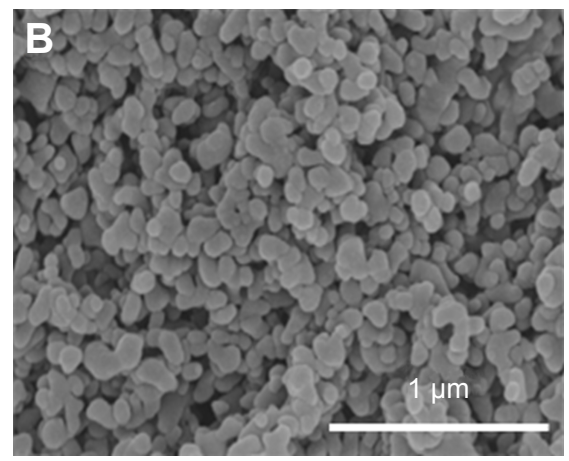

Figure 2 FE-SEM photographs of pure (A) and the SEDS process-assisted nanoparticulate forms (B) of methotrexate powder.

Note: Reprinted from J Supercrit Fluids. Vol 67. Chen AZ, Li L, Wang SB, et al. Nanonization of methotrexate by solution-enhanced dispersion by supercritical CO, Pages 7-13. Copyright 2012, with permission from Elsevier. ${ }^{59}$

Abbreviations: FE-SEM, field emission-scanning electron microscopy; SEDS, solution-enhanced dispersion by supercritical fluids. 


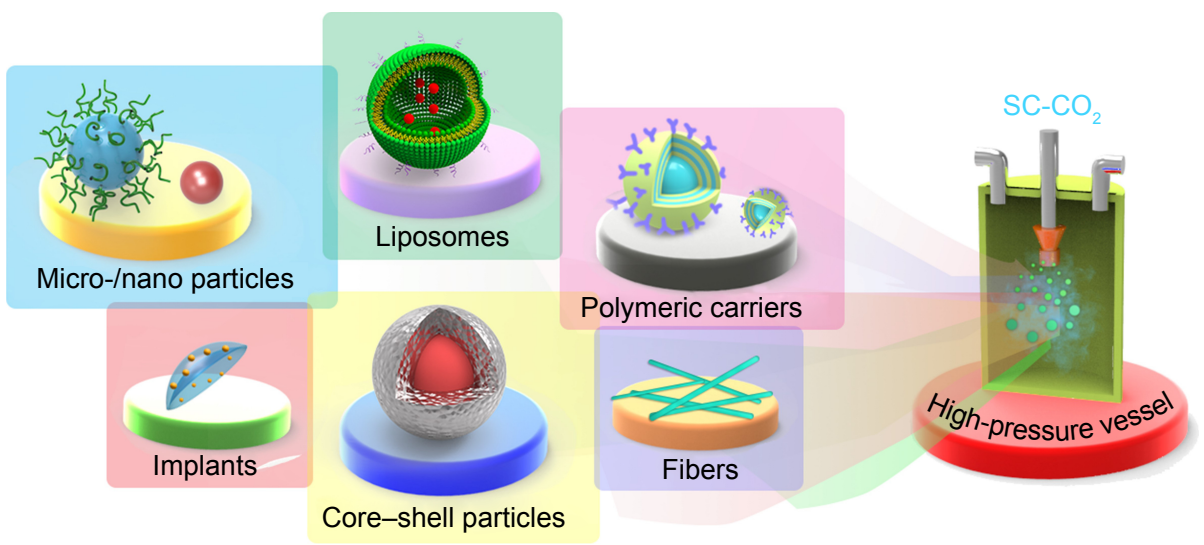

Figure 3 Schematic representation of formulations that have been synthesized by SEDS and its modified processes. Abbreviations: $\mathrm{SC}-\mathrm{CO}_{2}$, supercritical $\mathrm{CO}_{2}$; SEDS, solution-enhanced dispersion by supercritical fluids.

through co-precipitation or encapsulation strategy involve the momentous solvating power for the efficient separation of the desired mixture of polymers and drugs as micro- or nanosized particles. In this context, various biodegradable micro-/ nano-sized particles that have been prepared by SEDS and its modified processes are used as potential delivery systems to accomplish the therapeutic duties (Figure 3; Table 2). ${ }^{107}$ More often, active therapeutic moieties such as drugs, proteins, steroids, carotenoids, and organic pigments have been incorporated using various biodegradable polymeric carriers such as PLLA, PLGA, polyethylene glycol, chitosan, alginate, and lactose, among others, for their controlled delivery. ${ }^{10,52,91,92,108-110}$ This technology has a scope to adjust the size of the polymeric particles, which makes it highly feasible to attach the targeting ligands for the targeting efficacy, and their smaller size facilitates high dissolution rates and increases the bioavailability of the drugs. These consequences of high dissolution rates and bioavailability enhancement of the drugs subsequently facilitate the enhancement of their therapeutic efficiency at low dosage. ${ }^{107,111}$ The controlled release of drugs can generally be achieved through different mechanisms, which utterly depend on the method of choice for preparation as well as the type of the polymer selected. More often, the drugs co-precipitated/encapsulated by SEDS and its associated processes are released by slow diffusion from the polymeric matrix. In this framework, the interactions between the polymer and the drug often constitute electrostatic or weak hydrogen bonding interactions that are weakened when exposed to the solvent and facilitate drug release.

\section{Core-shell particles}

In the conventional SEDS process, the composite micro-/ nanoparticles formed during the co-precipitation of drug and polymer sometimes result in low drug loading as well as reduced encapsulation efficiency due to washes during depressurization and washing period. In addition, the drug molecules that are dispersed in the polymeric matrix are adsorbed on the surface of the polymer through weakly bound interactions, which often result in rapid release of the entire drug cargo ${ }^{66}$ To overcome these limitations, Chen et al fabricated the innovative core-shell formulations using the advanced SEDS process, that is, SpEDS, which resulted in improved drug loading efficiency and showed sustained drug release effect. ${ }^{29}$ In this process, the drug nanoparticles were initially produced and were then coated with the polymer to produce the core-shell composites. In addition, the authors demonstrated that this method of processing was highly advantageous over other SCF-assisted processes as the drug molecules in the core slowly diffused, after which the outer shell became porous or got degraded by the surrounding fluid. In some instances, rapid degradation phenomenon, that is, the burst-out process, was also achieved with $\mathrm{pH} /$ thermosensitive polymers. ${ }^{10}$

\section{Pulmonary delivery}

Biomacromolecules such as proteins, genes, and vaccines are the most promising therapeutic agents that should be delivered in right amounts to the desired sites without losing their biological activity, which results in higher efficacy and lower dosage requirement for administration. ${ }^{126,127}$ Pulmonary delivery of drugs is a considerable alternative for delivering such therapeutic, sensitive biomolecules as the lung is an appropriate site for the absorption of various therapeutic agents due to its high surface area, high vascularization, receipt of entire cardiac output, thin blood-alveolar barrier, lower enzyme activities, and circumventing the hepatic first-pass metabolism. ${ }^{10,122,128,129}$ More often, the pulmonary administration of various active moieties for localized as 
Table 2 Examples of drug-polymer conjugates obtained by the SEDS processing

\begin{tabular}{|c|c|c|c|c|}
\hline Material & Carrier & Solvent & Purpose of delivery & References \\
\hline 2,6-Dimethyl-8-(2-ethyl- & Mannitol, Eudragit ${ }^{\circledR}$ & Acetone, DMSO, $\mathrm{MeOH}$ & Bioavailability enhancement & 52 \\
\hline 6-methylbenzylamino)-3- & EI00 & & & \\
\hline \multicolumn{5}{|l|}{ hydroxymethylimidazo- } \\
\hline \\
\hline 5-Aminosalicylic acid & Eudragit SIOO & Acetone, DMSO & Controlled release & 68 \\
\hline \multirow[t]{3}{*}{ 5-Fluorouracil } & PLA & $\mathrm{DCM}, \mathrm{EtOH}$ & Controlled release & 91 \\
\hline & PLA, silica & DCM & & 112 \\
\hline & PEG, PLA-PEG & Water, acetone, DCM & & 113 \\
\hline$\beta$-Carotene & PHBV & DCM & Controlled release & $108-110$ \\
\hline Albuterol sulfate & Lactose & $\mathrm{MeOH}$ & Inhalation powders & 80 \\
\hline Amoxicillin & Chitosan & - & Bioavailability enhancement & 114 \\
\hline Budesonide & $\gamma-C D$ & $\mathrm{EtOH}$ & Bioavailability enhancement & 82,115 \\
\hline Celecoxib & PLGA & n-Butyl acetate, Water & Parenteral delivery & 28 \\
\hline Cefuroxime axetil & HPMC 29I0/PVP K-30 & DCM:EtOH $(6: 4$ w/w) & Bioavailability enhancement & 116 \\
\hline Curcumin & SF & HFIP & Bioavailability enhancement & 117,118 \\
\hline \multirow[t]{2}{*}{ Hydrocortisone } & PLGA, PLA, PCL & Acetone, chloroform, & Controlled release & 81 \\
\hline & & DCM, EA, isopropanol & & \\
\hline \multirow{2}{*}{ Indomethacin } & PLA, PLGA & DCM & Controlled release & 54 \\
\hline & $\mathrm{PLA}, \mathrm{Fe}_{3} \mathrm{O}_{4}$ & DCM & Magnetically responsive delivery & 48 \\
\hline Lutein & Zein & Acetone, DMSO (7:3 v/v) & Controlled release & 119 \\
\hline Lysozyme & PLA, PEG & DMSO:DCM (I:3 v/v) & Bioavailability enhancement & 94 \\
\hline \multirow[t]{2}{*}{ Methotrexate } & $\mathrm{SF}, \mathrm{Fe}_{3} \mathrm{O}_{4}$ & DCM, HFIP & Transdermal delivery & 120 \\
\hline & PLA-PEG-PLA & Acetone, DCM, DMSO & Controlled release & 29 \\
\hline \multirow[t]{2}{*}{ Morphine } & PLA-PEG-PLA & $\mathrm{DCM}, \mathrm{MeOH}$ & Controlled release & 121 \\
\hline & PLA & $\mathrm{DCM}$, EtOH, water & & 58 \\
\hline pDNA & Mannitol & Isopropanol & Inhalation powders & 122 \\
\hline \multirow[t]{2}{*}{ Paclitaxel } & FA-PEG-PLA & DCM & Targeted delivery & 123 \\
\hline & PLA, PLGA & DCM & Controlled release & 73 \\
\hline \multirow[t]{2}{*}{ Puerarin } & PLA & DCM & Controlled release & 66 \\
\hline & & DCM, EtOH & & 74 \\
\hline RNA & PLA-PEG, PLA & DCM & Transdermal controlled delivery & 124 \\
\hline Salmeterol xinafoate & Lactose & Acetone, $\mathrm{MeOH}, \mathrm{THF}$ & Inhalation powders & 78 \\
\hline Silymarin & Phospholipids & DCM:EtOH (I3:12 v/v) & Bioavailability enhancement & 125 \\
\hline
\end{tabular}

Abbreviations: CD, cyclodextrin; DCM, dichloromethane; DMSO, dimethyl sulfoxide; EA, ethyl acetate; EtOH, ethanol; FA, folic acid; HFIP, I,I,I,3,3,3-hexafluoro-2propanol; HPMC, hydroxypropyl methylcellulose; MeOH, methanol; PCL, polycaprolactone; PEG, polyethylene glycol; PLA, polylactic acid; PHBV, poly(3-hydroxybutyrateco-hydroxyvalerate); PLGA, poly(lactic-co-glycolic acid); PVP, polyvinylpyrrolidone; SEDS, solution-enhanced dispersion by supercritical fluids; SF, silk fibroin; THF, tetrahydrofuran; w/w, weight/weight; v/v, volume/volume.

well as systemic therapy is accomplished through various delivery containers such as dry powder inhalers, pressurized metered-dose inhalers, and nebulizers, loaded with powdered formulations. The size of particles plays a crucial role in fabricating the powders for inhalation delivery, and the acceptable size range of these powders should be $<7 \mu \mathrm{m}$ for their efficient deposition in the lungs. ${ }^{42,45,87,129}$ Among all these SCF-based processes, the SEDS process is one of the most effective methods in synthesizing pharmaceutical formulations intended for inhalation delivery. However, it should be noted that critical care should be taken for avoiding any residual amount of organic solvents, because these remnants may cause undesired severe immune responses in the lungs. In addition, the other notable point of concern that should be considered during the preparation of these delivery systems is strict optimization of the formulation for preserving the biological activity of therapeutic biomolecules. In one case, Tservistas et al prepared dry powder formulation of plasmid DNA using mannitol as the bulk excipient with the modified SEDS process. ${ }^{122}$ The prominent modification in the process was the utilization of three-channel coaxial nozzle, which resulted in the production of plasmid DNAloaded particles. Initially, the processed nucleic acid by this high-pressure technology resulted in degradation of the plasmid DNA. However, further investigations revealed that the $\mathrm{pH}$ of the medium played a crucial role in the retrieval of intact DNA, and eventually, the supercoiled proportion of DNA was recovered ( $80 \%) .{ }^{122}$ Many other studies have also reported that the synthesis of inhalation delivery systems of drugs and other therapeutic biomolecules such as genes and proteins was feasible via SEDS and its modified processes. ${ }^{78,80,122,130}$ 


\section{Transdermal and implantable delivery}

Drug delivery through transdermal route has attracted increasing interest from researchers due to its potential advantages such as circumventing the hepatic first-pass metabolism, sustained drug release, and localized treatment, among others. ${ }^{120,131-133}$ However, efficient permeation of drugs through the skin is highly limited by a barrier of protection called the stratum corneum. To overcome this limitation, several permeation enhancement techniques, including microneedle, ${ }^{131}$ electroporation, ${ }^{132}$ iontophoresis, ${ }^{134}$ and ultrasound pretreatment, ${ }^{133}$ among others, ${ }^{135}$ have been proposed for drug delivery and cosmetic application. ${ }^{135,136}$ Nevertheless, the applicability of these methods is limited due to their respective limitations, which have been discussed elsewhere. ${ }^{120}$ To this end, SCF-assisted preparations have been subjected to transdermal drug delivery with enhanced permeation efficiency as they possess several advantages such as high drug loading efficiency in the matrix through diffusion, plasticizing effect, high solubility, low amounts of residual solvent, and narrow as well as uniform particle size distribution resulting in improvement of solubility and permeation of drugs. ${ }^{137}$ In one case, Chen et al fabricated the silk fibroin (SF) magnetic nanoparticles using the SpEDS process for the delivery of methotrexate. ${ }^{10,127}$ The transdermal drug delivery was efficiently achieved through a synergistic approach utilizing the combination of the SEDS process-assisted SF nanoparticles with stationary/alternating magnetic fields. Remarkably, the synergistic combination of magnetic fields acting on the magnetic nanoparticles had created a massagelike effect on the skin for the penetration of carriers. ${ }^{127}$

Implantable drug delivery systems are incredible medical devices that are preloaded with drugs or other biomolecules and inserted into the body through surgical procedures for long-term therapeutics. More often, these systems are used for the treatment of postoperative complications such as infections and immune responses. ${ }^{10,138}$ In addition, these systemic delivery systems are recognized as a potential solution to address the issues associated with various other systemic routes of administration, such as frequent administration, adverse effects due to long-term treatment, and patient compliance. ${ }^{10,118,138}$ Various methods have been considered for producing the implantable systems, such as solvent casting process and hot-melt extrusion method, among others. ${ }^{10}$ However, these methods still face certain limitations such as high processing temperatures and remnants of organic solvents that provoke undesired immune responses when implanted. To this end, the SCF technology has attracted considerable interest from researchers for synthesizing these implants, by overcoming the above-mentioned limitations of conventional fabrication methods. This technology is highly beneficial in processing the APIs, the applicability of which is limited due to their poor pharmacokinetic behaviors, such as low solubility and, subsequently, low bioavailability. ${ }^{118}$ Interestingly, Xie et al developed an implantable polymeric nanofibrous drug delivery platform to enhance the bioavailability of natural polyphenolic compound curcumin $(\mathrm{CM})$ for effective cancer therapeutics. ${ }^{138}$ This active moiety is known for its effect on a wide range of cancers. In this study, the nanofibrous implantable matrices of CM-incorporated SF carriers by the SEDS process had resulted in controllable release of CM for topical cancer treatment (Figure 4). ${ }^{117,138}$

\section{Food and nutraceutical industries}

Due to its environmentally benign nature, the SCF technology has been widely used in various applications in health care field other than drug delivery. ${ }^{6,10}$ One among them is the

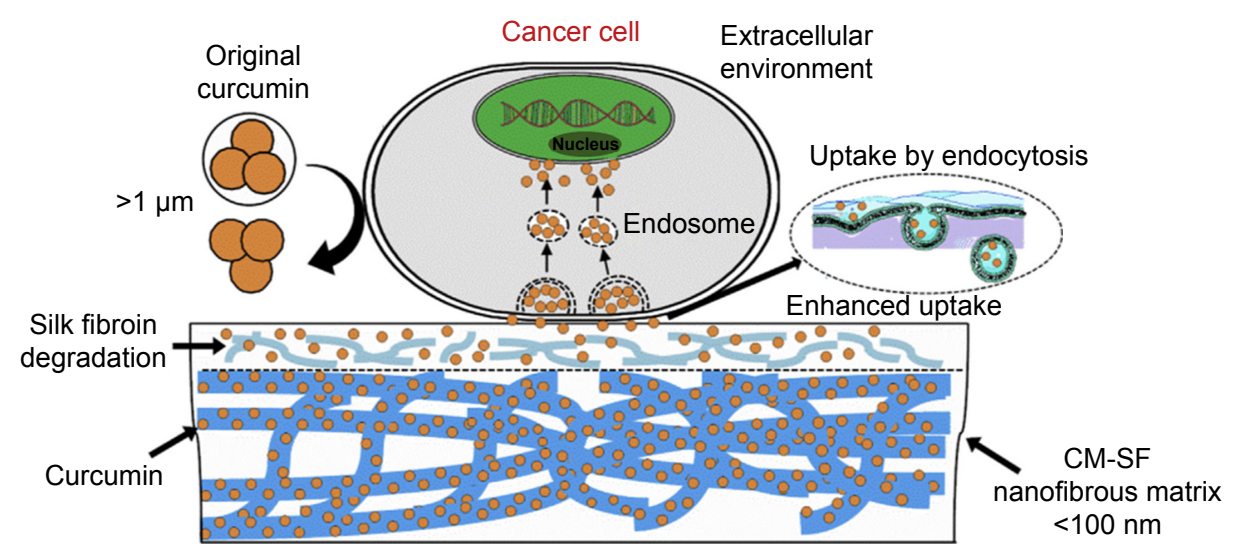

Figure 4 Schematic representation showing the mechanism of enhanced cellular uptake efficiency of implantable nanofibrous drug delivery platform by using the SEDS processing method.

Note: Reprinted from Biomaterials. Vol 103. Xie M, Fan D, Chen Y, et al. An implantable and controlled drug-release silk fibroin nanofibrous matrix to advance the treatment of solid tumour cancers. Pages 33-43. Copyright 2016, with permission from Elsevier. ${ }^{138}$

Abbreviations: CM-SF, curcumin-silk fibroin; SEDS, solution-enhanced dispersion by supercritical fluids. 
processing of diverse bioactive substances, that is, proteins and carotenoids, for nutraceutical applications, and also their encapsulation in biodegradable polymers to yield particles for the efficient delivery of nutrients. ${ }^{101}$ In addition, the biodegradable polymers coated over the biomolecules offer them significant protection from the harsh environments in the physiological fluids. Carotenoids, often referred to as nutraceutical compounds, are the most common group of pigments that are widely used in food and nutraceutical industries. ${ }^{101}$ More often, the presence of carotenoids can inhibit the oxidation of food constituents due to the singlet oxygen quenching activity. ${ }^{109}$ In addition, these substituents are used to improve the elegance of foods. However, the color intensity of the pigments utterly depends on their physicochemical properties such as particle size and its distribution and morphology. ${ }^{101,109}$ More often, these water-insoluble commercial carotenoids are present in their crystalline forms that are often processed by using oils and organic solvents, which may lead to the contamination of food and nutrients. To this end, this ecofriendly process can overcome the limitation of food contamination. The SEDS process is the most efficient method for the processing of carotenoids, as this strategy is operated at near-ambient conditions and in an inert environment, where there is no scope of thermal degradation of sensitive carotenoids. ${ }^{65,139}$ Unlike other conventional methods, the SCF-based processes do not rely on the organic solvents. The micronization or nanonization of these nutraceutical moieties by SEDS results in improvement of their solubility due to the enhanced surface area of exposure in the solvents. ${ }^{6,10}$ However, it is evident that the applicability of synthetic pigments is restricted due to the health hazards in the food, cosmetic, and pharmaceutical industries. In a case, Hong et al micronized the natural pigment, astaxanthin, by using the solution-enhanced dispersion by supercritical fluids - prefilming atomization method. ${ }^{139}$ The authors demonstrated that this natural pigment was preferred owing to its different biological functions such as ultraviolet light protection, antioxidant, and anti-inflammatory effects, among others. ${ }^{139}$ Moreover, the authors claimed that various experimental variables such as initial concentration of the solute, solution flow rate, and critical conditions had shown significant influence in the determination of morphology and particle size of astaxanthin particles. ${ }^{70}$

The processing of these nutraceutical moieties by traditional fabrication methods often results in undesired effects due to the presence of double bonds in the molecular chains of carotenoids. ${ }^{109}$ In this framework, the exposure of these sensitive molecules to heat, light, and acids may result in the isomerization of trans-carotenoids (the stable form), which get converted to their cis-form, which are comparatively inferior to the trans-form (ie, diminished color, reduced pro-vitamin activity, and eventually, their efficacy)..$^{109,140,141}$ The encapsulation and co-precipitation of these proteins/carotenoids in biodegradable polymers by the SEDS process is the most efficient method to preserve the effects as well as enhance their efficiency. ${ }^{109,119}$ In addition, further advancements have been made in formulating the nano-sized inclusion complexes with $\beta$-cyclodextrin using the SEDS process. ${ }^{140}$ At optimized conditions, the lycopene/ $\beta$-CD nanoparticles of $40 \mathrm{~nm}$ were obtained at high temperature and pressure with a low solution flow rate, resulting in enhancement of both the solubility and stability of lycopene.

\section{Conclusion}

In summary, the review has given the insights of the SEDS process in generating micro-/nano-sized APIs or their polymeric conjugates that can be administered through oral, pulmonary, and transdermal routes. Furthermore, the specialized formulations such as core-shell formulations and implantable nanofibrous delivery systems have been systematically reviewed. The delivery systems produced by this process are highly advantageous over products that are obtained by other processing techniques of the SCF technology resulting in products with better performances. In addition, we emphasized the effects of various parameters on the particle morphology during SEDS processing.

Despite its success and significant advantages, the SEDS method still faces a significant impediment regarding its processing for scale-up due to the lack of fundamental studies that precisely describe the phase behavior and performance of the multicomponent mixtures. In addition, the certainty of particle characteristics, which include the solubility enhancement of microparticles produced by this process, remains as an obstacle. Therefore, we envision that integrating the conventional process with the SCF process may result in further advancements of the carriers. In addition, it may surpass the complexity of the processing and enable better understanding of the behavioral characteristics of the product. However, with continued innovations, we believe that a promising formulation of biodegradable micro-/nanosized particles from these SCF-assisted processes will soon become commercially available.

\section{Acknowledgments}

The authors acknowledge the financial support from National Natural Science Foundation of China (U1605225, 31570974, and 31470927), Public Science and Technology Research Funds Projects of Ocean (201505029), Promotion Program 
for Young and Middle-aged Teacher in Science and Technology Research of Huaqiao University (ZQN-PY107), and the Start-Up Fund For Young Researchers (Project No 16BS803).

\section{Disclosure}

The authors report no conflicts of interest in this work.

\section{References}

1. Bałdyga J, Kubicki D, Shekunov BY, Smith KB. Mixing effects on particle formation in supercritical fluids. Chem Eng Res Des. 2010; 88(9):1131-1141.

2. Kompella UB, Koushik K. Preparation of drug delivery systems using supercritical fluid technology. Crit Rev Ther Drug Carrier Syst. 2001; 18(2):173-199.

3. Chen BQ, Kankala RK, Chen AZ, et al. Investigation of silk fibroin nanoparticle-decorated poly(1-lactic acid) composite scaffolds for osteoblast growth and differentiation. Int J Nanomedicine. 2017;12:1877-1890.

4. Hauthal WH. Advances with supercritical fluids [review]. Chemosphere. 2001;43(1):123-135.

5. Chen AZ, Zhao Z, Wang SB, Li Y, Zhao C, Liu YG. A continuous RESS process to prepare PLA-PEG-PLA microparticles. J Supercrit Fluids. 2011;59:92-97.

6. Ginty PJ, Whitaker MJ, Shakesheff KM, Howdle SM. Drug delivery goes supercritical. Mater Today. 2005;8(8):42-48.

7. Ginty PJ, Howard D, Rose FRAJ, et al. Mammalian cell survival and processing in supercritical $\mathrm{CO}_{2}$. Proc Natl Acad Sci. 2006;103(19):7426-7431.

8. Pasquali I, Bettini R. Are pharmaceutics really going supercritical? Int J Pharm. 2008;364(2):176-187.

9. Kalani M, Yunus R. Application of supercritical antisolvent method in drug encapsulation: a review. Int J Nanomedicine. 2011;6:1429-1442.

10. Kankala RK, Zhang YS, Wang SB, Lee CH, Chen AZ. Supercritical fluid technology: an emphasis on drug delivery and related biomedical applications. Adv Healthc Mater. 2017;6(16):1700433.

11. Wu K, Li J. Precipitation of a biodegradable polymer using compressed carbon dioxide as antisolvent. J Supercrit Fluids. 2008;46(2):211-216.

12. Davies OR, Lewis AL, Whitaker MJ, Tai H, Shakesheff KM, Howdle SM. Applications of supercritical $\mathrm{CO}_{2}$ in the fabrication of polymer systems for drug delivery and tissue engineering. Adv Drug Del Rev. 2008;60(3):373-387.

13. Reverchon E, Adami R. Nanomaterials and supercritical fluids. J Supercrit Fluids. 2006;37(1):1-22.

14. Byrappa K, Ohara S, Adschiri T. Nanoparticles synthesis using supercritical fluid technology - towards biomedical applications. Adv Drug Del Rev. 2008;60(3):299-327.

15. Hakuta $Y$, Hayashi $H$, Arai K. Fine particle formation using supercritical fluids. Curr Opin Solid State Mater Sci. 2003;7(4-5):341-351.

16. Meziani MJ, Rollins HW, Allard LF, Sun YP. Protein-protected nanoparticles from rapid expansion of supercritical solution into aqueous solution. J Phys Chem B. 2002;106(43):11178-11182.

17. Warwick B, Dehghani F, Foster NR, Biffin JR, Regtop HL. Micronization of copper indomethacin using gas antisolvent processes. Ind Eng Chem Res. 2002;41(8):1993-2004.

18. Kröber H, Teipel U. Materials processing with supercritical antisolvent precipitation: process parameters and morphology of tartaric acid. J Supercrit Fluids. 2002;22(3):229-235.

19. Perry RH. Perry's Chemical Engineers' Handbook. 7th ed. New York, NY: McGraw-Hill; 1997.

20. Djerafi R, Masmoudi Y, Crampon C, Meniai A, Badens E. Supercritical anti-solvent precipitation of ethyl cellulose. J Supercrit Fluids. 2015; 105:92-98.

21. Tomasko DL, Li H, Liu D, et al. A review of $\mathrm{CO}_{2}$ applications in the processing of polymers. Ind Eng Chem Res. 2003;42(25):6431-6456.
22. Vemavarapu C, Mollan MJ, Lodaya M, Needham TE. Design and process aspects of laboratory scale SCF particle formation systems. Int J Pharm. 2005;292(1-2):1-16.

23. Matson DW, Fulton JL, Petersen RC, Smith RD. Rapid expansion of supercritical fluid solutions: solute formation of powders, thin films, and fibers. Ind Eng Chem Res. 1987;26(11):2298-2306.

24. Fraile M, Martín Ÿ, Deodato D, et al. Production of new hybrid systems for drug delivery by PGSS (Particles from Gas Saturated Solutions) process. J Supercrit Fluids. 2013;81:226-235.

25. Bertucco A, Pallado P, Benedetti L. Formation of biocompatible polymer microspheres for controlled drug delivery by a supercritical antisolvent technique. Process Technol Proc. 1996;12:217-222.

26. Falk R, Randolph TW, Meyer JD, Kelly RM, Manning MC. Controlled release of ionic compounds from poly (1-lactide) microspheres produced by precipitation with a compressed antisolvent. $J$ Control Release. 1997;44(1):77-85.

27. Yeo SD, Lim GB, Debendetti PG, Bernstein H. Formation of microparticulate protein powder using a supercritical fluid antisolvent. Biotechnol Bioeng. 1993;41(3):341-346.

28. Margulis K, Neofytou EA, Beygui RE, Zare RN. Celecoxib nanoparticles for therapeutic angiogenesis. ACS Nano. 2015;9(9):9416-9426.

29. Chen AZ, Wang GY, Wang SB, Li L, Liu YG, Zhao C. Formation of methotrexate-PLLA-PEG-PLLA composite microspheres by microencapsulation through a process of suspension-enhanced dispersion by supercritical $\mathrm{CO}_{2}$. Int J Nanomedicine. 2012;7:3013-3022.

30. Chen AZ, Lin XF, Wang SB, et al. Biological evaluation of $\mathrm{Fe}_{3} \mathrm{O}_{4}^{-}$ poly(L-lactide)-poly(ethylene glycol)-poly(L-lactide) magnetic microspheres prepared in supercritical $\mathrm{CO}_{2}$. Toxicol Lett. 2012;212(1): $75-82$.

31. Chattopadhyay P, Gupta RB. Supercritical $\mathrm{CO}_{2}$ based production of magnetically responsive micro- and nanoparticles for drug targeting. Ind Eng Chem Res. 2002;41(24):6049-6058.

32. Beckman EJ. Supercritical and near-critical $\mathrm{CO}_{2}$ in green chemical synthesis and processing. J Supercrit Fluids. 2004;28(2-3):121-191.

33. Reverchon E. Supercritical-assisted atomization to produce microand/or nanoparticles of controlled size and distribution. Ind Eng Chem Res. 2002;41(10):2405-2411.

34. Shen YB, Du Z, Wang Q, Guan YX, Yao SJ. Preparation of chitosan microparticles with diverse molecular weights using supercritical fluid assisted atomization introduced by hydrodynamic cavitation mixer. Powder Technol. 2014;254:416-424.

35. García-González CA, Concheiro A, Alvarez-Lorenzo C. Processing of materials for regenerative medicine using supercritical fluid technology. Bioconju Chem. 2015;26(7):1159-1171.

36. Yang D, Luo W, Wang J, et al. A novel controlled release formulation of the Pin1 inhibitor ATRA to improve liver cancer therapy by simultaneously blocking multiple cancer pathways. J Control Release. 2018; 269:405-422.

37. Bleich J, Kleinebudde P, Müller BW. Influence of gas density and pressure on microparticles produced with the ASES process. Int J Pharm. 1994;106(1):77-84.

38. Mishima K. Biodegradable particle formation for drug and gene delivery using supercritical fluid and dense gas. Adv Drug Del Rev. 2008; 60(3):411-432.

39. Adami R, Reverchon E, Järvenpää E, Huopalahti R. Supercritical antisolvent micronization of nalmefene $\mathrm{HCl}$ on laboratory and pilot scale. Powder Technol. 2008;182(1):105-112.

40. Campardelli R, Adami R, Della Porta G, Reverchon E. Nanoparticle precipitation by supercritical assisted injection in a liquid antisolvent. Chem Eng J. 2012;192:246-251.

41. Della Porta G, Falco N, Reverchon E. NSAID drugs release from injectable microspheres produced by supercritical fluid emulsion extraction. J Pharm Sci. 2010;99(3):1484-1499.

42. York P, Hanna M. Particle engineering by supercritical fluid technologies for powder inhalation drug delivery. Paper presented at: Proceedings of the Conference on Respiratory Drug Delivery 1996; Phoenix, Arizona. 
43. Jung J, Perrut M. Particle design using supercritical fluids: literature and patent survey. J Supercrit Fluids. 2001;20(3):179-219.

44. Mishima K, Matsuyama K, Tanabe D, Yamauchi S, Young TJ, Johnston KP. Microencapsulation of proteins by rapid expansion of supercritical solution with a nonsolvent. AIChE J. 2000;46(4): 857-865.

45. Shoyele SA, Cawthorne S. Particle engineering techniques for inhaled biopharmaceuticals. Adv Drug Deliv Rev. 2006;58(9-10):1009-1029.

46. Bałdyga J, Czarnocki R, Shekunov BY, Smith KB. Particle formation in supercritical fluids-Scale-up problem. Chem Eng Res Des. 2010; 88(3):331-341.

47. Yan T, Cheng Y, Wang Z, Huang D, Miao H, Zhang Y. Preparation and characterization of baicalein powder micronized by the SEDS process. J Supercrit Fluids. 2015;104:177-182.

48. Chen AZ, Kang YQ, Pu XM, Yin GF, Li Y, Hu JY. Development of $\mathrm{Fe}_{3} \mathrm{O}_{4}$-poly(l-lactide) magnetic microparticles in supercritical $\mathrm{CO}_{2}$ $J$ Colloid Interface Sci. 2009;330(2):317-322.

49. Nerome H, Machmudah S, Wahyudiono, et al. Nanoparticle formation of lycopene $/ \beta$-cyclodextrin inclusion complex using supercritical antisolvent precipitation. J Supercrit Fluids. 2013;83:97-103.

50. Li S, Zhao Y. Preparation of zein nanoparticles by using solutionenhanced dispersion with supercritical $\mathrm{CO}_{2}$ and elucidation with computational fluid dynamics. Int J Nanomedicine. 2017;12 3485-3494.

51. Palakodaty S, York P, Pritchard J. Supercritical fluid processing of materials from aqueous solutions: the application of SEDS to lactose as a model substance. Pharm Res. 1998;15(12):1835-1843.

52. Juppo AM, Boissier C, Khoo C. Evaluation of solid dispersion particles prepared with SEDS. Int J Pharm. 2003;250(2):385-401.

53. Hooton JC, German CS, Allen S, et al. Characterization of particleinteractions by atomic force microscopy: effect of contact area. Pharm Res. 2003;20(3):508-514.

54. Kang Y, Wu J, Yin G, et al. Preparation, characterization and in vitro cytotoxicity of indomethacin-loaded PLLA/PLGA microparticles using supercritical $\mathrm{CO}_{2}$ technique. Eur J Pharm Biopharm. 2008; 70(1):85-97.

55. Chen AZ, Wang GY, Wang SB, Feng JG, Liu YG, Kang YQ. Preparation of Poly-(Methyl vinyl ether-co-maleic Anhydride) nanoparticles by solution-enhanced dispersion by supercritical $\mathrm{CO}_{2}$. Materials (Basel). 2012;5(10):1841-1852.

56. Suo QL, He WZ, Huang YC, et al. Micronization of the natural pigmentbixin by the SEDS process through prefilming atomization. Powder Technol. 2005;154(2-3):110-115.

57. Xiao K, Wang W, Hu D, Qu Y, Hao Z, Wang L. Cefquinome controlled size submicron particles precipitation by SEDS process using annular gap nozzle. Int J Chem Eng. 2017;2017:1-8.

58. Zhang YZ, Liao XM, Yin GF, et al. Preparation of water soluble drugsloaded microparticles using modified solution enhanced dispersion by supercritical $\mathrm{CO}_{2}$. Powder Technol. 2012;221:343-350.

59. Chen AZ, Li L, Wang SB, et al. Nanonization of methotrexate by solution-enhanced dispersion by supercritical $\mathrm{CO}_{2} . J$ Supercrit Fluids. 2012;67:7-13.

60. Rantakylä M, Jäntti M, Aaltonen O, Hurme M. The effect of initial drop size on particle size in the supercritical antisolvent precipitation (SAS) technique. J Supercrit Fluids. 2002;24(3):251-263.

61. He WZ, Suo QL, Hong HL, et al. Supercritical antisolvent micronization of natural carotene by the SEDS process through prefilming atomization. Ind Eng Chem Res. 2006;45(6):2108-2115.

62. He W, Jiang Z, Suo Q, Li G. Mechanism of dispersing an active component into a polymeric carrier by the SEDS-PA process. J Mater Sci. 2009; $45(2): 467$

63. He WZ, Suo QL, Jiang ZH, Shan A, Hong HL. Precipitation of ephedrine by SEDS process using a specially designed prefilming atomizer. J Supercrit Fluids. 2004;31(1):101-110.

64. He WZ, Jiang ZH, Suo QL. Analysis of energy efficiency of air in atomizing pseudoplastic liquid using a specially designed prefilming airblast atomizer. Ind Eng Chem Res. 2003;42(13):3144-3149.
65. Jin HY, Hemingway M, Xia F, Li SN, Zhao YP. Production of $\beta$-carotene nanoparticles by the solution enhanced dispersion with enhanced mass transfer by ultrasound in supercritical $\mathrm{CO}_{2}$ (SEDS-EM). Ind Eng Chem Res. 2011;50(23):13475-13484.

66. Chen AZ, Li Y, Chau FT, et al. Microencapsulation of puerarin nanoparticles by poly(l-lactide) in a supercritical $\mathrm{CO}_{2}$ process. Acta Biomater. 2009;5(8):2913-2919.

67. Chen AZ, Pu XM, Kang YQ, Liao L, Yao YD, Yin GF. Study of poly(1lactide) microparticles based on supercritical $\mathrm{CO}_{2}$.J Mater Sci Mater Med. 2007;18(12):2339-2345.

68. Hu D, Liu L, Chen W, Li S, Zhao Y. A novel preparation method for 5-aminosalicylic acid loaded Eudragit S100 nanoparticles. Int J Mol Sci. 2012;13(5):6454-6468.

69. Machado FRS Jr, Reis DF, Boschetto DL, et al. Encapsulation of astaxanthin from Haematococcus pluvialis in PHBV by means of SEDS technique using supercritical $\mathrm{CO}_{2}$. Ind Crops Prod. 2014;54: $17-21$.

70. Hong HL, Suo QL, Li FW, Wei XH, Zhang JB. Precipitation and characterization of chelerythrine microparticles by the supercritical antisolvent process. Chem Eng Technol. 2008;31(7):1051-1055.

71. Moshashaee S, Bisrat M, Forbes RT, Nyqvist H, York P. Supercritical fluid processing of proteins. I: lysozyme precipitation from organic solution. Eur J Pharm Sci. 2000;11(3):239-245.

72. Hong HL, Suo QL, Lang ZM, Han LM, Li CP. Micronization of the officinal component emodin via the SEDS process through prefilming atomization. Cryst Res Technol. 2008;43(5):502-507.

73. Kang Y, Yin G, Ouyang P, et al. Preparation of PLLA/PLGA microparticles using solution enhanced dispersion by supercritical fluids (SEDS). J Colloid Interface Sci. 2008;322(1):87-94.

74. Chen AZ, Li Y, Chau FT, et al. Application of organic nonsolvent in the process of solution-enhanced dispersion by supercritical $\mathrm{CO}_{2}$ to prepare puerarin fine particles. J Supercrit Fluids. 2009;49(3):394-402.

75. Velaga SP, Berger R, Carlfors J. Supercritical fluids crystallization of budesonide and flunisolide. Pharm Res. 2002;19(10):1564-1571.

76. Chen AZ, Kang YQ, Wang SB, Tang N, Su XQ. Preparation and antitumor effect evaluation of composite microparticles co-loaded with siRNA and paclitaxel by a supercritical process. J Mater Chem B. 2015; 3(31):6439-6447.

77. Ghaderi R, Artursson P, Carlfors J. Preparation of biodegradable microparticles using solution-enhanced dispersion by supercritical fluids (SEDS). Pharm Res. 1999;16(5):676-681.

78. Shekunov BY, Feeley JC, Chow AHL, Tong HHY, York P. Aerosolisation behaviour of micronised and supercritically-processed powders. J Aerosol Sci. 2003;34(5):553-568.

79. Richardson CH, de Matas M, Hosker H, Mukherjee R, Wong I, Chrystyn H. Determination of the relative bioavailability of salbutamol to the lungs following inhalation from dry powder inhaler formulations containing drug substance manufactured by supercritical fluids and micronization. Pharm Res. 2007;24(11):2008-2017.

80. Schiavone H, Palakodaty S, Clark A, York P, Tzannis ST. Evaluation of SCF-engineered particle-based lactose blends in passive dry powder inhalers. Int J Pharm. 2004;281(1-2):55-66.

81. Ghaderi R, Artursson P, Carlfors J. A new method for preparing biodegradable microparticles and entrapment of hydrocortisone in $\mathrm{dl}-$ PLG microparticles using supercritical fluids. Eur J Pharm Sci. 2000; 10(1):1-9.

82. Toropainen T, Heikkilä T, Leppänen J, et al. Crystal Structure Changes of $\gamma$-cyclodextrin after the SEDS process in supercritical carbon dioxide affect the dissolution rate of complexed budesonide. Pharm Res. 2007;24(6):1058-1066.

83. Hooton JC, German CS, Allen S, et al. An atomic force microscopy study of the effect of nanoscale contact geometry and surface chemistry on the adhesion of pharmaceutical particles. Pharm Res. 2004;21(6): 953-961.

84. Torino E, De Marco I, Reverchon E. Organic nanoparticles recovery in supercritical antisolvent precipitation. J Supercrit Fluids. 2010; 55(1):300-306. 
85. Moribe K, Tozuka Y, Yamamoto K. Supercritical carbon dioxide processing of active pharmaceutical ingredients for polymorphic control and for complex formation. Adv Drug Deliv Rev. 2008;60(3): 328-338

86. Okamoto H, Danjo K. Application of supercritical fluid to preparation of powders of high-molecular weight drugs for inhalation. Adv Drug Del Rev. 2008;60(3):433-446.

87. Pasquali I, Bettini R, Giordano F. Supercritical fluid technologies: an innovative approach for manipulating the solid-state of pharmaceuticals. Adv Drug Del Rev. 2008;60(3):399-410.

88. Ma T, Zhang YS, Chen A, et al. Carbon dioxide-assisted bioassembly of cell-loaded scaffolds from polymeric porous microspheres. J Supercrit Fluids. 2017;120(1):43-51.

89. Zhang A, Zhang Q, Bai H, Li L, Li J. Polymeric nanoporous materials fabricated with supercritical $\mathrm{CO}_{2}$ and $\mathrm{CO}_{2}$-expanded liquids. Chem Soc Rev. 2014;43(20):6938-6953.

90. Chen BQ, Kankala RK, Wang SB, Chen AZ. Continuous nanonization of lonidamine by modified-rapid expansion of supercritical solution process. J Supercrit Fluids. 2018;133(1):486-493.

91. Chen AZ, Pu XM, Kang YQ, Liao L, Yao YD, Yin GF. Preparation of 5-Fluorouracil-Poly(L-lactide) microparticles using solution-enhanced dispersion by supercritical $\mathrm{CO}_{2}$. Macromol Rapid Commun. 2006;27(15): 1254-1259.

92. Franceschi E, De Cesaro AM, Ferreira SRS, Vladimir Oliveira J. Precipitation of $\beta$-carotene microparticles from SEDS technique using supercritical $\mathrm{CO}_{2}$. J Food Eng. 2009;95(4):656-663.

93. Chen AZ, Pu XM, Yin GF, et al. Study of lysozyme-polymer composite microparticles in supercritical $\mathrm{CO}_{2}$. J Appl Polym Sci. 2012;125(4): 3175-3183.

94. Xie M, Fan D, Zhao Z, et al. Nano-curcumin prepared via supercritical: Improved anti-bacterial, anti-oxidant and anti-cancer efficacy. Int $J$ Pharm. 2015;496(2):732-740.

95. Zhao Z, Xie M, Li Y, et al. Formation of curcumin nanoparticles via solution-enhanced dispersion by supercritical $\mathrm{CO}_{2}$. Int J Nanomedicine. 2015;10:3171-3181.

96. Velaga SP, Carlfors J. Supercritical fluids processing of recombinant human growth hormone. Drug Dev Ind Pharm. 2005;31(2): 135-149.

97. Nesta DP, Elliott JS, Warr JP. Supercritical fluid precipitation of recombinant human immunoglobulin from aqueous solutions. Biotechnol Bioeng. 2000;67(4):457-464.

98. Kodama T, Honda M, Takemura R, et al. Effect of the Z-isomer content on nanoparticle production of lycopene using solution-enhanced dispersion by supercritical fluids (SEDS). J Supercrit Fluids. 2018; 133(1):291-296.

99. Miao H, Chen Z, Xu W, Wang W, Song Y, Wang Z. Preparation and characterization of naringenin microparticles via a supercritical antiSolvent process. J Supercrit Fluids. 2018;131:19-25.

100. Rehman M, Shekunov BY, York P, Colthorpe P. Solubility and precipitation of nicotinic acid in supercritical carbon dioxide. J Pharm Sci. 2001;90(10):1570-1582.

101. Quan C, Johan C, Charlotta T. Carotenoids particle formation by supercritical fluid technologies. Chin J Chem Eng. 2009;17(2):344-349.

102. Aguiar GPS, Boschetto DL, Chaves LMPC, et al. Trans-resveratrol micronization by SEDS technique. Ind Crops Prod. 2016;89:350-355.

103. Richardson $\mathrm{CH}$, de Matas M, Hosker H, Mukherjee R, Wong I, Chrystyn H. Determination of the relative bioavailability of salbutamol to the lungs following inhalation from dry powder inhaler formulations containing drug substance manufactured by supercritical fluids and micronization. Pharm Res. 2007;24(11):2008-2017.

104. Elizondo E, Sala S, Imbuluzqueta E, et al. High loading of gentamicin in bioadhesive PVM/MA nanostructured microparticles using compressed carbon-dioxide. Pharm Res. 2011;28(2): 309-321.

105. Guney O, Akgerman A. Synthesis of controlled-release products in supercritical medium. AIChE J. 2002;48(4):856-866.
106. Uhrich KE, Cannizzaro SM, Langer RS, Shakesheff KM. Polymeric systems for controlled drug release. Chem Rev. 1999;99(11): 3181-3198.

107. Baldelli A, Boraey MA, Nobes DS, Vehring R. Analysis of the particle formation process of structured microparticles. Mol Pharm. 2015;12(8): 2562-2573.

108. Priamo WL, de Cezaro AM, Benetti SC, Oliveira JV, Ferreira SRS. In vitro release profiles of $\beta$-carotene encapsulated in PHBV by means of supercritical carbon dioxide micronization technique. J Supercrit Fluids. 2011;56(2):137-143.

109. Priamo WL, de Cezaro AM, Ferreira SRS, Oliveira JV. Precipitation and encapsulation of $\beta$-carotene in PHBV using carbon dioxide as anti-solvent. J Supercrit Fluids. 2010;54(1):103-109.

110. Franceschi E, De Cesaro AM, Feiten M, et al. Precipitation of $\beta$-carotene and PHBV and co-precipitation from SEDS technique using supercritical $\mathrm{CO}_{2}$. J Supercrit Fluids. 2008;47(2):259-269.

111. Tien YC, Su CS, Lien LH, Chen YP. Recrystallization of erlotinib hydrochloride and fulvestrant using supercritical antisolvent process. J Supercrit Fluids. 2010;55(1):292-299.

112. Chen AZ, Li Y, Chen D, Hu JY. Development of core-shell microcapsules by a novel supercritical $\mathrm{CO}_{2}$ process. J Mater Sci Mater Med. 2009;20(3):751-758.

113. Zhang C, Li G, Wang Y, Cui F, Zhang J, Huang Q. Preparation and characterization of 5-fluorouracil-loaded PLLA-PEG/PEG nanoparticles by a novel supercritical $\mathrm{CO}_{2}$ technique. Int J Pharm. 2012;436(1-2): 272-281.

114. Patel J, Patil P. Preparation and characterization of amoxicillin mucoadhesive microparticles using solution-enhanced dispersion by supercritical $\mathrm{CO}_{2}$. J Microencapsul. 2012;29(4):398-408.

115. Toropainen T, Velaga S, Heikkilä T, et al. Preparation of budesonide $/ \gamma-$ cyclodextrin complexes in supercritical fluids with a novel SEDS method. J Pharm Sci. 2006;95(10):2235-2245.

116. Jun SW, Kim MS, Jo GH, et al. Cefuroxime axetil solid dispersions prepared using solution enhanced dispersion by supercritical fluids. J Pharm Pharmacol. 2005;57(12):1529-1537.

117. Xie MB, Li Y, Zhao Z, et al. Solubility enhancement of curcumin via supercritical $\mathrm{CO}_{2}$ based silk fibroin carrier. J Supercrit Fluids. 2015; 103:1-9.

118. Xie M, Li Y, Zhao Z, et al. Development of silk fibroin-derived nanofibrous drug delivery system in supercritical $\mathrm{CO}_{2}$. Mater Lett. 2016; 167:175-178.

119. Hu D, Lin C, Liu L, Li S, Zhao Y. Preparation, characterization, and in vitro release investigation of lutein/zein nanoparticles via solution enhanced dispersion by supercritical fluids. J Food Eng. 2012;109(3): 545-552.

120. Chen AZ, Chen LQ, Wang SB, Wang YQ, Zha JZ. Study of magnetic silk fibroin nanoparticles for massage-like transdermal drug delivery. Int J Nanomedicine. 2015;10:4639-4651.

121. Chen F, Yin G, Liao X, et al. Preparation, characterization and in vitro release properties of morphine-loaded PLLA-PEG-PLLA microparticles via solution enhanced dispersion by supercritical fluids. JMater Sci Mater Med. 2013;24(7):1693-1705.

122. Tservistas M, Levy MS, Lo-Yim MY, et al. The formation of plasmid DNA loaded pharmaceutical powders using supercritical fluid technology. Biotechnol Bioeng. 2001;72(1):12-18.

123. Huang X, Zhang Y, Yin G, et al. Tumor-targeted paclitaxel-loaded folate conjugated poly(ethylene glycol)-poly(L-lactide) microparticles produced by supercritical fluid technology. J Mater Sci Mater Med. 2015;26(2):95.

124. Jacobson GB, Gonzalez-Gonzalez E, Spitler R, et al. Biodegradable nanoparticles with sustained release of functional siRNA in skin. J Pharm Sci. 2010;99(10):4261-4266.

125. Yang G, Zhao Y, Zhang Y, Dang B, Liu Y, Feng N. Enhanced oral bioavailability of silymarin using liposomes containing a bile salt: preparation by supercritical fluid technology and evaluation in vitro and in vivo. Int J Nanomedicine. 2015;10:6633-6644. 
126. Okamoto H, Danjo K. Application of supercritical fluid to preparation of powders of high-molecular weight drugs for inhalation. Adv Drug Deliv Rev. 2008;60(3):433-446.

127. Chen AZ, Tang N, Wang SB, Kang YQ, Song HF. Insulin-loaded poly-L-lactide porous microspheres prepared in supercritical $\mathrm{CO}_{2}$ for pulmonary drug delivery. J Supercrit Fluids. 2015;101:117-123.

128. Patton JS, Trinchero P, Platz RM. Special issue proceedings of the sixth international symposium on recent advances in drug delivery systems bioavailability of pulmonary delivered peptides and proteins: $\alpha$-interferon, calcitonins and parathyroid hormones. J Control Release. 1994;28(1):79-85.

129. Lipworth BJ. Pharmacokinetics of inhaled drugs. Br J Clin Pharmacol. 1996;42(6):697-705

130. Rehman M, Shekunov BY, York P, et al. Optimisation of powders for pulmonary delivery using supercritical fluid technology. Eur J Pharm Sci. 2004;22(1):1-17.

131. Sivamani RK, Liepmann D, Maibach HI. Microneedles and transdermal applications. Expert Opin Drug Deliv. 2007;4(1):19-25.

132. Denet AR, Vanbever R, Preat V. Skin electroporation for transdermal and topical delivery. Adv Drug Deliv Rev. 2004;56(5):659-674.

133. Park EJ, Werner J, Smith NB. Ultrasound mediated transdermal insulin delivery in pigs using a lightweight transducer. Pharm Res. 2007; 24(7):1396-1401

134. Mayes S, Ferrone M. Fentanyl $\mathrm{HCl}$ patient-controlled iontophoretic transdermal system for the management of acute postoperative pain. Ann Pharmacother. 2006;40(12):2178-2186.
135. Prausnitz MR, Langer R. Transdermal drug delivery. Nat Biotechnol. 2008;26(11):1261-1268.

136. García-González CA, Sampaio da Sousa AR, Argemí A, et al. Production of hybrid lipid-based particles loaded with inorganic nanoparticles and active compounds for prolonged topical release. Int $J$ Pharm. 2009;382(1-2):296-304.

137. Duarte ARC, Mano JF, Reis RL. Preparation of chitosan scaffolds loaded with dexamethasone for tissue engineering applications using supercritical fluid technology. Eur Polym J. 2009;45(1):141-148.

138. Xie M, Fan D, Chen Y, et al. An implantable and controlled drugrelease silk fibroin nanofibrous matrix to advance the treatment of solid tumour cancers. Biomaterials. 2016;103:33-43.

139. Hong HL, Suo QL, Han LM, Li CP. Study on precipitation of astaxanthin in supercritical fluid. Powder Technol. 2009;191(3):294-298.

140. Nerome H, Machmudah S, Wahyudiono, et al. Nanoparticle formation of lycopene/ $\beta$-cyclodextrin inclusion complex using supercritical antisolvent precipitation. J Supercrit Fluids. 2013;83(Suppl C):97-103.

141. Jain A, Thakur D, Ghoshal G, Katare OP, Shivhare US. Microencapsulation by complex coacervation using whey protein isolates and gum acacia: an approach to preserve the functionality and controlled release of $\beta$-carotene. Food Bioprocess Technol. 2015;8(8):1635-1644.
International Journal of Nanomedicine

\section{Publish your work in this journal}

The International Journal of Nanomedicine is an international, peerreviewed journal focusing on the application of nanotechnology in diagnostics, therapeutics, and drug delivery systems throughout the biomedical field. This journal is indexed on PubMed Central, MedLine, CAS, SciSearch ${ }^{\circledR}$, Current Contents ${ } /$ Clinical Medicine,

\section{Dovepress}

Journal Citation Reports/Science Edition, EMBase, Scopus and the Elsevier Bibliographic databases. The manuscript management system is completely online and includes a very quick and fair peer-review system, which is all easy to use. Visit http://www.dovepress.com/ testimonials.php to read real quotes from published authors. 